\title{
Therapeutic Strategies for SLE Involving Cytokines: Mechanism-Oriented Therapies Especially IFN- $\gamma$ Targeting Gene Therapy
}

\author{
Toshiharu Hayashi \\ Laboratory of Veterinary Pathology, Faculty of Agriculture, Yamaguchi University, 1677-1 Yoshida, Yamaguchi 753-8515, Japan \\ Correspondence should be addressed to Toshiharu Hayashi, hayasi@yamaguchi-u.ac.jp
}

Received 25 January 2010; Accepted 25 June 2010

Academic Editor: Brian Poole

Copyright (C) 2010 Toshiharu Hayashi. This is an open access article distributed under the Creative Commons Attribution License, which permits unrestricted use, distribution, and reproduction in any medium, provided the original work is properly cited.

\begin{abstract}
Systemic lupus erythematosus (SLE: lupus) is a chronic complicated autoimmune disease and pathogenesis is still unclear. However, key cytokines have been recognized. Interferon (IFN)- $\gamma$ and also IFN $\alpha / \beta$ are of particular importance. Depending on the concept that lupus is a helper $\mathrm{T}(\mathrm{Th}) 1$ disease and that dendritic cells (DCs) determine the direction of lupus, balance shift of Th1/Th2 and immunogenic/tolerogenic DCs is reviewed for therapy. (IFN)- $\gamma$ - and IFN- $\alpha / \beta$-targeted (gene) therapies are introduced. These consist of Th1/Th2 balance shift and elimination of IFN- $\gamma$ and IFN- $\gamma$-related cytokines such as (interleukin)IL12 and IL-18. Other approaches include suppression of immunocompetent cells, normalization of abnormal T-cell function, costimulation blockade, B lymphocyte stimulator (Blys) blockade, and suppression of nephritic kidney inflammation. Moreover, balance shift of IFN- $\alpha / \beta$ and tumor necrosis factor (TNF)- $\alpha$ together with regulatory $\mathrm{T}$ (Treg) cells are briefely introduced. Clinical application will be discussed.
\end{abstract}

\section{Introduction}

Systemic lupus erythematosus (SLE or lupus) is a disorder of immune regulation characterized by the breakdown of selftolerance. The complexities of various humoral and cellular abnormalities under the influence with predisposing genetic, sex hormonal and environmental factors have been reported in pathogenesis of SLE in human and model animals [1, 2]. In general, patients with overt disease will be treated with immunosuppressants (e.g., prednisolone, cyclophosphamide, and tacrolimus) or NSAIDs (nonsteroidal antiinflammatory drugs). Those immunosuppressive drugs are strongly effective in prevention of the development of lupus nephritis due to reducing the host immune responses. However, less toxic approaches to avoid severe adverse events (infections, infertility, amenorrhea, and metabolic abnormalities) are remained $[3,4]$. Thus, there are a lot of trialsfocusing on improved therapy compared to classic immunosuppressive drugs in experimental basis [5].

Amoura et al. [6] have recently reviewed new biotherapies that new approaches in human lupus are based on a better understanding of the autoimmune response as follows. Targets of these new treatments are all steps of the immune response in lupus development. These are (1) "B lymphocyte (BL)" inhibitors such as anti-CD20 monoclonal antibody, anti-CD22 monoclonal antibody, Blymphocyte stimulator (BlyS) antagonists, tolerogenic peptide [hCDR1: Edratide, which is based on the sequence of the complementary-determining region (CDR) 1 of a human anti-DNA monoclonal antibody that bears the major idiotype designated 16/6Id] [7], and LJP 394 (abetimus sodium) which selectively reduces antibodies to dsDNA and their parent B cells via antigen-specific tolerance [1]; (2) "Inhibitors of the costimulation" between antigenpresenting cells and $\mathrm{T}$ lymphocyte by monoclonal anti-CD40 ligand antibody or CTLA-4-Ig; (3) "Cytokine antagonists" inhibiting key cytokines of SLE: IL-10 [8], interferon (IFN)$\alpha$ [9], which are associated with lupus in human [10], IL-6 [11] and tumor necrosis factor (TNF)- $\alpha$ [12]. In addition, the importance of IL-23/IL-17 axis in human lupus and lupus model mice is pointed out $[13,14]$ and the possibility of IL17 targeted therapy is recently proposed since its important 


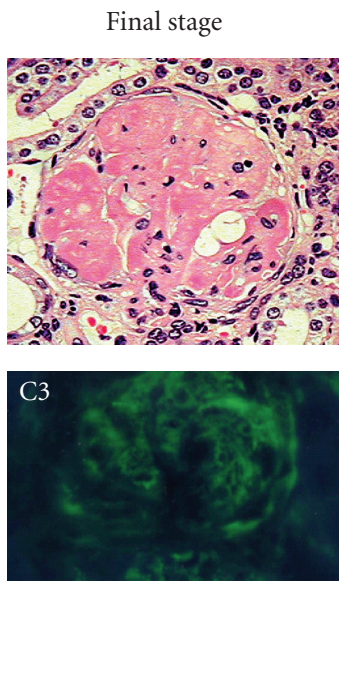

Figure 1: Class-switcing of immunoglobulin. Cognate contact of T-B interaction and following stimulation of cytokines determine Ig subclass switching in mouse.

role in human SLE [4]. Steinmetz et al. [15] showed for the first time that not only Th1, but also Th17 effector T cells mediate glomerulonephritis in lupus model MRL/lpr mice. They showed that deficiency of the chemokine receptor CXCR3-bering T cells (highly expressed on Th1 cells) leads to significant morphological and functional improvement of nephritic kidneys. Thus, all of those are expected as an effective new therapy in lupus-like tumor necrosis factor (TNF)$\alpha$ targeted therapy in clinical application for rheumatoid arthritis (RA) [7, 16]. Obviously, effectiveness is reported by the treatment of anti-IL10 mAb [8], LJP 394 [17], Edratide [7], inhibition of T cell costimulation [18] and antiIFN $\alpha / \beta[19]$ in human lupus. On the other hand, Mohrs et al. [20] have reviewed that fusion proteins, peptides, and small molecules rather than therapeutic antibodies which are excellent alternative tools for immune intervention in lupus.

Alternatively, immune regulation forming cytokine networks including intracellular signaling of cytokines is highly complex and the mechanisms of regulation is not as yet fully understood in lupus pathogenesis [21, 22]. Moreover, compared to organ-specific autoimmune diseases, several organs/tissues (e.g., Kidneys, lungs, joints, nervous systems, and serous membranes) are involved in SLE. Also, patients with SLE were often accompanied with secondary Sögren's syndrome ( $\mathrm{sSjS}$ ) [23]. In each organ involved, pathogenesis is quite different. For example, humoral immunity plays a role in capillary damages in glomeruli, lungs, dermal tissues [24] and other organs whereas cell-mediated immunity develops in interstitium of kidneys, lacrimal, and salivary glands in lupus with sSjS, resulting in damages of those organs [25]. These suggest that therapy focusing on one cytokine (or combination of several cytokines) or one immunocompetent cell seems to be difficult. Thus, the concept is very important by cytokine targeted therapy.
Blocking a single cytokine might be the best to control this clinically heterogeneous disease in lupus. Depending on the concept of balance shift, this review introduces [I] alteration of the balance between Th1 (IFN- $\gamma)$ and Th2 cell (IL-4) activity $[28,29]$ (Figure 1), but not shift proinflammatory versus immunosuppressive cytokine profiles (IL1, IL-6, IL-10, TNF- $\alpha$ ) and [II] shift from immunogenic $($ IFN- $\alpha / \beta)$ to tolerogenic (TNF- $\alpha$ ) DCs (Figure 2) in lupusprone mice. Moreover, informative data are involved in section $[\mathrm{I}]$, despite those are different from the concept. The clinical implications including usefulness and unfavorable side effects in those therapies are discussed in each section.

\section{[I] Th1/Th2 Balance Shift}

[1] Lupus is a Th1-Dominant Disease. Several cytokines and chemokines are involved in the lupus pathogenesis $[13,30]$ as described above. More than 30 years ago, Hooks et al. [31] found immune interferon (IFN- $\gamma$ ) in the sera of patients with SLE and showed a good correlation between immune IFN- $\gamma$ titers and disease activity. Moreover, IFN- $\gamma$ titers correlated positively with antibodies to DNA and negatively with serum levels of third components of complement. After that, however, the dominance of Th1 or Th2 cytokines in SLE patients and lupus model mice has been debated in numerous reports over time until now. Earlier reports proposed a Th2 response (especially IL-4) (or a mixed Th1 and Th2 response) [1, 32-35] whereas recent evidences demonstrated the importance of the Th1 response especially IFN- $\gamma$ (see [36-41] Figure 1), including IFN- $\gamma$ inducible IL$12[42,43]$ and IL-18 [44, 45]. Those are involved in the onset and progression of the autoimmune disease in lupus. Moreover, the current consensus is that IL-4 production is not increased in SLE patients by cDNA assay [46]. One might suppose that the autoimmune manifestations of the SLE 


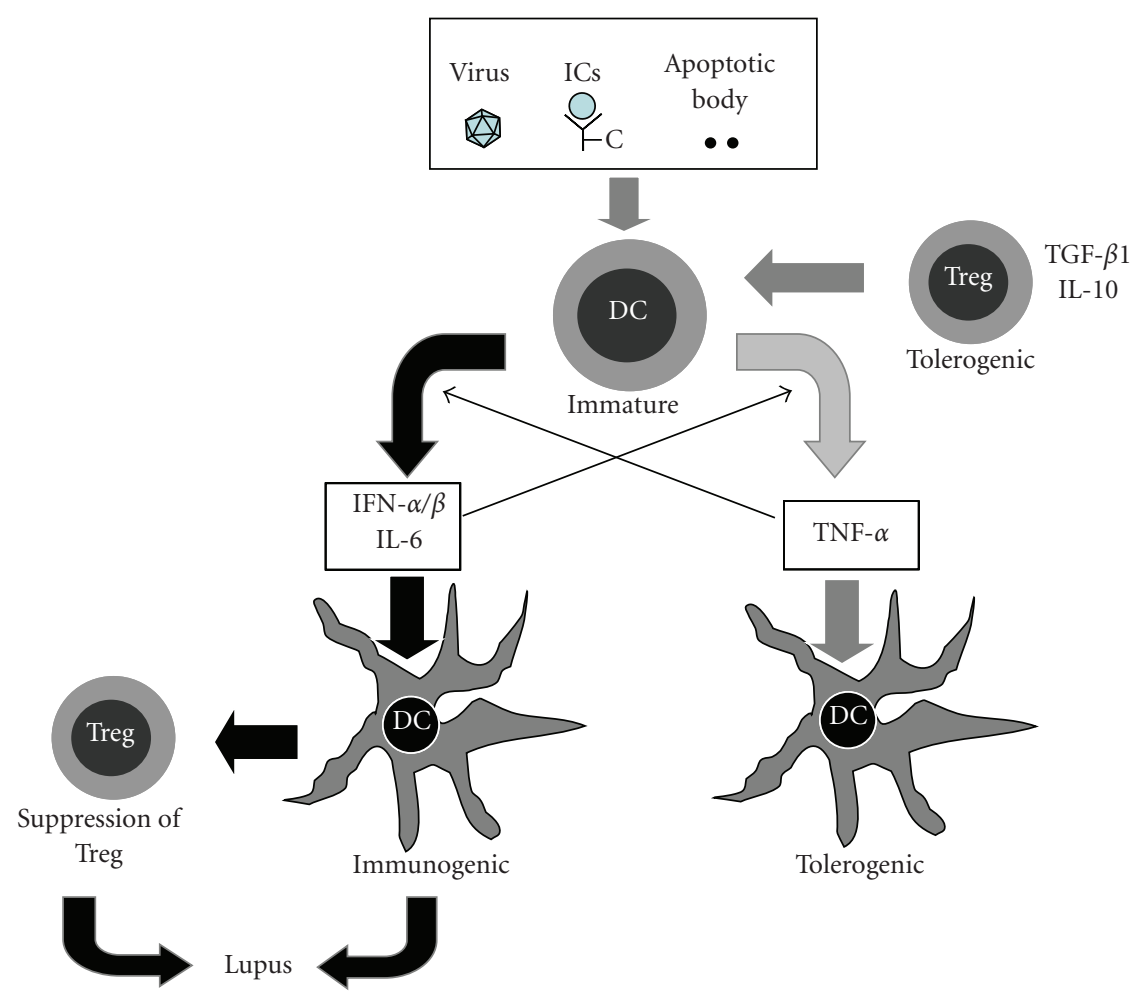

FIGURE 2: Notion of IFN $-\alpha / \beta$ and TNF- $\alpha$ axis balance proposed by Banchereau and Pascual [26]. Environmental factors (e.g., viral infections), apoptotic bodies and immune complexes stimulate pDCs through the coengagement of Fc $\gamma$ R and TLRs trigger the production of IFN $-\alpha / \beta$ from $\mathrm{pDCs}$ and following production of TNF- $\alpha$ occurs. Also IFN- $\alpha / \beta$ induces the generation of mature DCs. Banchereau and Pascud hypothesize that increased production of TNF- $\alpha$ may weaken IFN- $\alpha / \beta$ production, leading to prevention of lupus. Also tolerogenic peptide activates Treg cells leading to production of TGF- $\beta$ may inhibit DCs activity, resulting in the suppression of lupus development [27]. These events suppress the lupus development, whereas immunogenic DCs suppress function of Treg cells. Thus Horwitz [22] proposed T reg regulation together with tolerogenic DCs for therapy. Important cytokines are shown in bold arrows letters.

are not based solely on a Th1 type autoimmune response, since Th2 type cytokines such as IL-6, which promotes the terminal differentiation from activated B cells to antibody producing plasma cells, are apparently involved [11, 47]. In addition, proinflammatory cytokines (e.g., IL-1, TNF- $\alpha$ ) [12] are also involved other than Th1 and Th2 cytokines. Shimizu et al. [48] reported the evidences that MRL/lpr mice develop diffuse proliferative glomerulonephritis similar to that in human lupus nephritis (WHO class IV) was associated with autoimmune responses dominated by IFN- $\gamma$, whereas MRL/lpr mice lacking WSX-1 gene, which encodes a subunit of the IL-27R with homology to IL-12R, developed disease resembling human membranous glomerulonephritis (WHO class V) with a predominance of IgG1 in glomerular deposits, accompanied by increased IgG1 and IgE in the sera.

Furthermore, late stages of murine lupus characterized by renal fibrosis (glomerulosclerosis) have been considered a Th2-mediated disease [49].

In fact, many immune responses do not reflect an absolute Th1 or Th2 pattern as described above, but functionally dominated by either Th1 (especially IFN- $\gamma$ ) or Th2 (especially IL-4) cytokines in immune disease are pointed out by Paul and Seder [50]. At present, there are general agreements that initiation of events in the early and following phases of nephritis is due to Th1- and Th1-related cytokines, and therefore, an altered ratio of IFN- $\gamma / \mathrm{IL}-4$ producing.

Th cell axis could determine the nature, strength, and duration of systemic autoimmune responses in lupus nephritis [1].

\section{[2] IFN- $\gamma$ Targeted Therapy}

(1) Synthetic Oligodeoxynucleotides (ODN). It has been reported that suppressive synthetic oligodeoxynucleotides (ODN) containing TTAGGG motifs, which are found at high frequency in the telomeric region of mammalian chromosomes [52], can downregulate inflammatory responses that are injurious to the host $[53,54]$. Sano et al. [55] have reported ODN without $\mathrm{CpG}$ motifs, a 6-base DNA motif consisting of an unmethylated $\mathrm{CpG}$ dinucleotide flanked by tow $5^{\prime}$ purines and two $3^{\prime}$ pyrimidines, work as adjuvant for the induction of Th2 differentiation in a sequenceindependent manner [56].

Dong et al. [57] reported that synthetic ODN delay the onset of glomerulonephritis and prolong survival in lupusprone $\mathrm{B} / \mathrm{WF}_{1}$ mice, which is one of excellent mouse models for human lupus (Figure 3 ) with a significant reduction in productions of anti-dsDNA autoantibody, IFN- $\gamma$, and IL-12. 


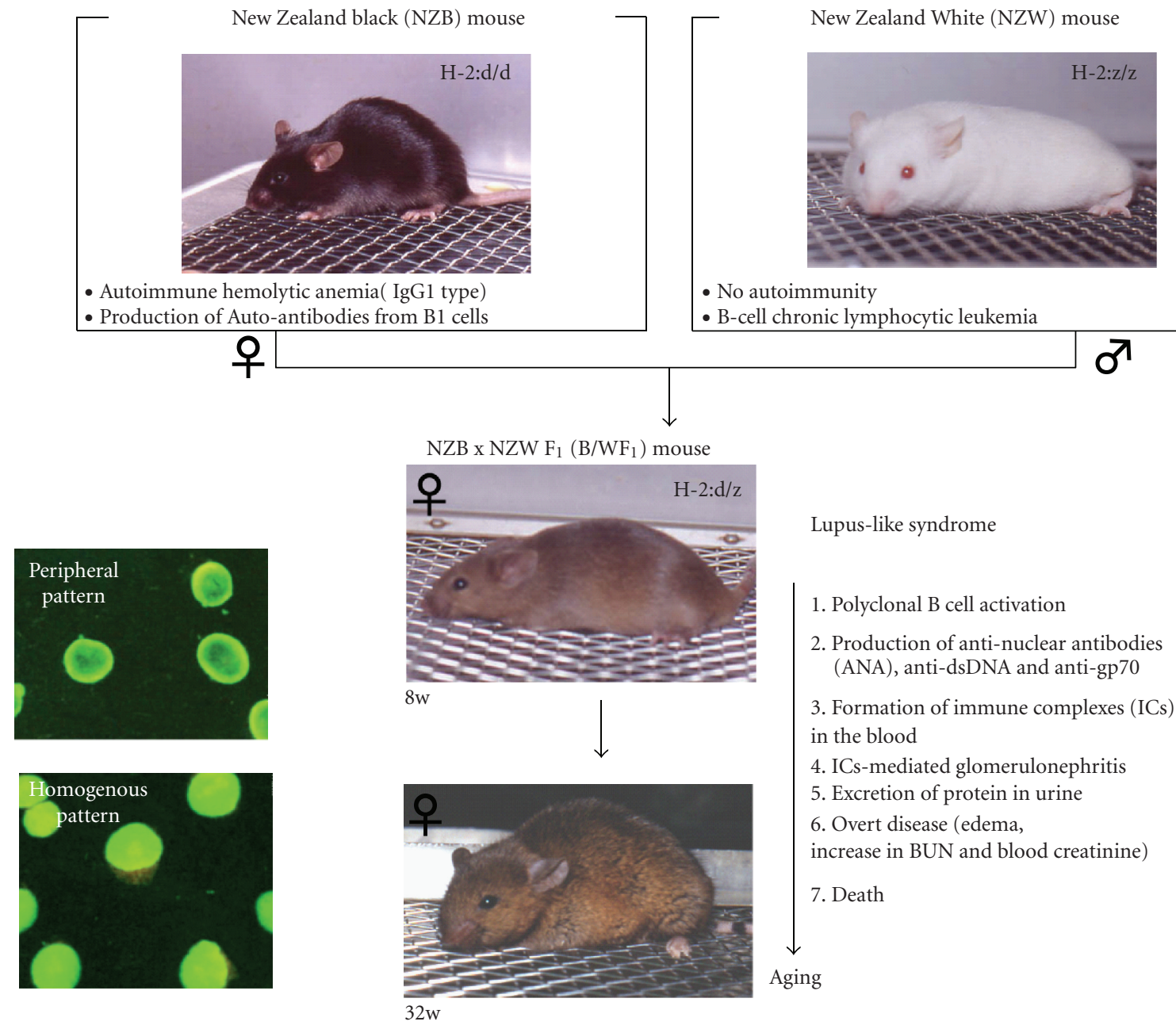

FIGURE 3: Female B/WF $\mathrm{W}_{1}$ mice constitute one of the best-studied animal models of spontaneous systemic lupus erythematosus (SLE) in human. Their characteristic features include polyclonal B-cell activation, production of autoantibodies against autoantigens (e.g., notably dsDNA), which occur when the animals are 5-6 months of age, and development of glomerulonephritis with age which is the major cause of death due to renal failure. Moreover, animals respond to cortisone similar to human patients with SLE [51]. H-2: mouse MHC. ANA: antinuclear antibody.

In addition, production of proinflammatory cytokines, especially IL- 6 was blocked by those treatments. Also, repeatedly treated mice with suppressive ODN before or after the onset of proteinuria significantly prolonged lifespan with delaying the onset and progression of glomerulonephritis in $\mathrm{B} / \mathrm{WF}_{1}$ mice. Clinical improvement was accompanied by a significant reduction in anti-dsDNA autoantibody production and by significantly reduced secretion of IFN- $\gamma$ and IL-12 in vivo. They monitored body weight and general activity as measures of animal well-being by these general criteria, suppressive ODN did not adversely impact animal health (data not shown). They concluded that suppressive ODN may be of benefit in the treatment of chronic systemic autoimmune diseases such as SLE.

Although, the mechanism by which suppressive ODN block ongoing inflammatory immune responses is incompletely understood, suppressive ODN may directly block the signal transduction cascade associated with the production of IFN- $\gamma$ and IL-12, thereby influencing the Th1/Th2 balance in vivo [56]. In light of evidence that suppressive ODN slows the development of organ-specific autoimmune Th1 diseases in autoimmune type 1 diabetes (T1D) animal models, suggesting that these agents may be broadly useful in the prevention and treatment of diseases characterized by the overproduction of Th1 and/or inflammatory cytokines. In this report, the sensitivity against pathogens and Th2dependent allergic diseases is unclear.

(2) Bioactive Th2 Cytokines (IL-4 and IL-10). Suppression of IFN- $\gamma$ by recombinant (r)IL- 4 or rIL-10 may be effective to preventive lupus. However, a large dose and frequent administrations of rIL-4 are necessary to maintain the effective concentration of IL-4 on prevention of T1D in murine models $[58,59]$, since its half life is very short $(t 1 / 2$ $=19 \pm 2 \mathrm{~min})$ in the circulation in mice administrated intravenously by murine rIL-4 [60]. A large dose of rIL-4 
or rIL-10 $(t 1 / 2=$ several hours $)[61]$ as the use of Th1/Th2 balance shaft may evoke unexpected side effects in recipients, such as disturbance of host immune states due to temporal large amounts. In addition, the therapy by use of those bioactive cytokines is very expensive. Thus, at present, there is no report using those in lupus model and human lupus.

(3) Anti-IL10 Antibody. Llorente et al. [8] showed firstly in their pilot study that elimination of IL-10 (one of Th2 cytokines) by murine monoclonal antibody ( $\mathrm{mAb}$ ) to human patients $(20 \mathrm{mg} /$ day intravenous administration of an antiIL-10 murine mAb (B-N10) for 21 consecutive days) with SLE led to a rapid decrease of disease, which was maintained for 6 months of followup. The study indicates that the use of IL-10 antagonists may be beneficial in the management of refractory SLE. They discussed that this study appears encouraging to justify a larger, randomized, and blinded study using a humanized anti-IL-10 $\mathrm{mAb}$ to determine whether this approach allows reduction of corticosteroid treatment including the determination of long-term control of the disease by repeated administration of an anti-IL-10 in patients with poorly controlled SLE.

IL-10, which is considered to be anti-inflammatory, has properties that are somewhat ambivalent, since it can stimulate the immune function of some cell populations and is a potent anti-inflammatory cytokine with strong inhibitory effects on Th1 cells and inflammatory reactions [62]. However, lupus patients with pulmonary involvement have a higher proinflammatory cytokines profile IL-6, IL-8, IL-10, IL-12, IFN- $\gamma$, and TNF- $\alpha$, suggesting the involvement of IL-10 in many facets of development and prognosis of SLE. If that is the case, anti-IL-10 antibody may contribute to suppress lupus by the different mechanisms other than the concept of Th1/Th2 balance shift.

(4) IL-4 Transgene. To address the issue of whether IL4 -induced immune deviation can provide protection from ongoing lupus, Santiago et al. [63] reported protective effect on the development of lupus-like glomerulonephritis in the $(\mathrm{NZW} \times \mathrm{B} 6 \cdot \mathrm{Yaa}) \mathrm{F}_{1}$ murine model of SLE expressing constitutively an IL-4 transgene (pEP-IL-4) by B cells [64], since this would help establish new strategies for the development of therapeutic approaches in SLE and related human autoimmune diseases.

They showed protection that occurred in association with marked changes in the IgG subclasses rather than in total levels of anti-DNA autoantibodies, with an absence of IgG3 and a decrease of IgG2a subclasses. This was accompanied by a similar modulatory antibody response of the IgG subclass antibody against T-cell-dependent antigen (heataggregated human IgG: $\mathrm{HGG}$ ), but not T-cell-independent antigen (LPS: lipopolysaccharide). The decrease of IgG3 and IgG2a autoantibody production in the transgenic mice is most likely due to the inhibitory effect of IL- 4 on the development of the Th1 subset, suggesting downregulation of Th1 autoimmune responses by IL- 4 , although they did not show values of Th1 and Th2 cytokines. This approach may be applicable as one of strategies for the therapeutic approaches in SLE and related human autoimmune diseases.

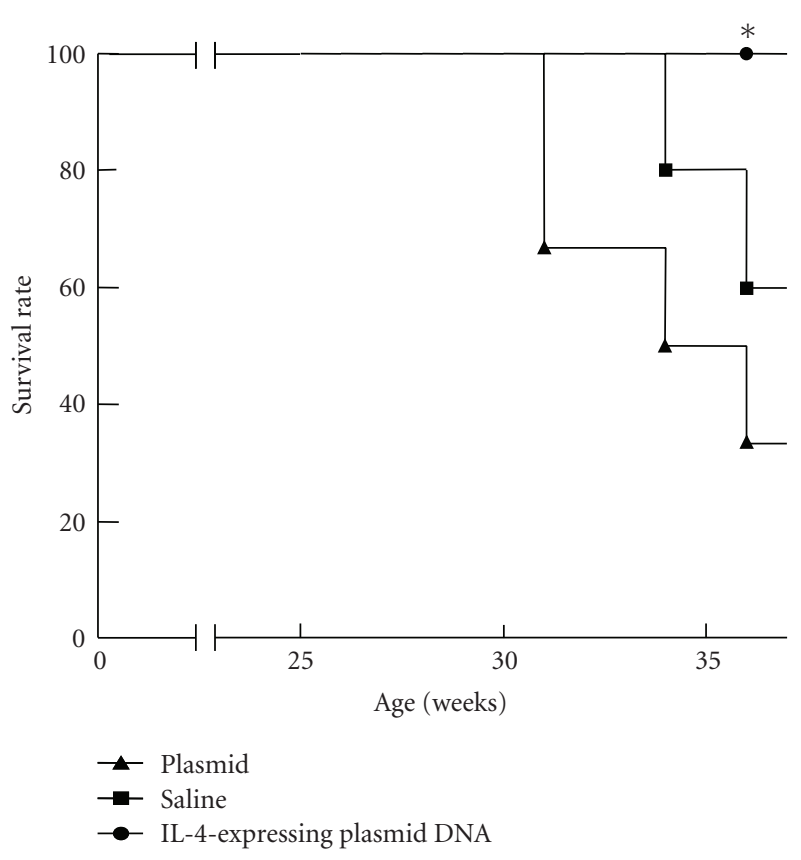

FIgURE 4: Survival rate among three groups. Mice were treated intraperitoneally either with $100 \mu \mathrm{g}$ of the IL-4pDNA, $100 \mu \mathrm{g}$ of plasmid only or saline only at the age of $4,6,8,12,16,20,24$, 28 and 32 weeks. ${ }^{*} P<.001$ (comparison between the IL-4pDNA group and two controls). Provided here is courtesy of NDT 2007, 22, 3131-8: Oxford University Press).

However, pEP-IL-4 transgenic mice are more susceptible to Leishmania major infection than nontransgenic mice [65] in which Th1 cells play a crucial role in protection against $\mathrm{L}$. major infection [66]. Also, they pointed out that it will be important to determine whether IL-4 transgene expression also leads to protection against SLE in other murine models such as $\mathrm{B} / \mathrm{WF}_{1}$ and MRL-lpr/lpr mice, in terms of the issue of whether IL-4-induced immune deviation can provide protection from ongoing disease [67].

(5) IL-4-Expressing Plasmid DNA. We have reported that preventive effects of IL-4-expressing plasmid DNA (pIL-4) using the plasmid vector PCGGS (kindly supplied by Dr. Miyazaki), on lupus development in lupus-prone female $\mathrm{B} / \mathrm{WF}_{1}$ mice [68]. IL-10-expressing DNA plasmid, which prevent T1D in model mouse [69], was not used, because as described in section [I]-(3), the use of it seems to be complicated in lupus. Successful prevention of pIL-4 in T1D experimental animal model $[58,70]$ encourages us for application to lupus. $\mathrm{B} / \mathrm{WF}_{1}$ mice monthly injected repeatedly with the IL-4p DNA intraperitoneally before and after the active phase drastically delayed the development of glomerulonephritis with deposits of IgG2a and C3 leading to excretion of urine protein, and they showed prolonged survival (Figure 4). Clinical improvement was associated with the reduction in productions of IgG antidsDNA autoantibodies with reduction of IFN- $\gamma$ production and slightly increased IL-4 production from splenic cell, suggesting IL-4pDNA administration may delay lupus onset 
and progress by shifting from Th1 to Th2 responses. In addition, CRFK cell line transfected with the IL-4pDNA produced enough concentration of IL-4 (approximately $200 \mathrm{pg} / \mathrm{mL}$ ) more than 8 days in vitro. Thus, compared to the administration of the bioactive recombinant IL-4, IL4 pDNA may be advantageous and useful for the reduction of Th1-dependent autoimmune diseases including lupus. On the other hand, the plasmid accelerated, to some extent, the lupus development compared to the nontreated control group. It seems likely, since $\mathrm{B} / \mathrm{WF}_{1}$ mice administrated with plasmid containing many CpG motifs [71], which promote lupus [47], may interact and stimulate a variety of immune cells, and then those cells may secrete mainly Th1 (IFN- $\gamma$ ) and Th1-related cytokines (IL-12 and IL-18) including IL$6[72,73]$. However, values of IL-4 produced by IL-4pDNA may be higher than those of IFN- $\gamma$ production by $\mathrm{CpG}$ ODN stimulation. As a result, IFN- $\gamma$ production may be inhibited by mutual inhibitory effects of Th1/Th2 cytokines [28]. In addition, CpG ODN may have a possibility to produce anti-DNA antibody formation [73]. However, this possibility may be negligible, since anti-dsDNA production in the IL-4pDNA-treated mice was reduced. Moreover, long-time survived mice did not show any clinical signs such as a dull movement and a loss of hair glittering by renal failure, supporting that idea. Also, there was no development of systemic Th2 response by this treatment like alum adjuvant (aluminium hydroxide gel), which itself induces strong systemic Th2 response (unpublished data). In this experiment which cell type takes up the IL-4pDNA after injection intraperitoneally is unknown. Thus, further study is needed to clarify cell types, including efficiency of transfection, which cells take up the IL-4pDNA and how long the expression of the IL-4pDNA lasts, including how secreted IL- 4 protein affects IL- 4 receptor since the IL- $4 \alpha$ receptorchain is a component of both the IL- 4 and the IL-13 receptor [20].

Mazda [74] have reported that nonviral gene transfer technologies include naked DNA administration, electrical or particle-mediated transfer of naked DNA such as low immunogenicity, inexpensiveness, and ease in handling, but the common disadvantage is the transfection efficiency. It remains to be determined whether an optimal dose of pIL4 will have beneficial effects on autoreactive $\mathrm{T}$ and $\mathrm{B}$ cells without compromising immunity to foreign antigens.

(6) IL-5 Transgene. IL-5 preferentially activates B1 cells to produce natural antibodies cross-reactive to self antigens [75]. Wen et al. [76] have reported that $\mathrm{B} / \mathrm{WF}_{1}$ mice congenic for IL-5 transgene (TG-F1) reduced the incidence of lupus nephritis with decreased anti-DNA antibodies and those produced by splenic B cells in vitro. As TG-F1 mice aged, frequencies of peripheral B1 cells progressively increased, and the mice frequently developed B-cell chronic lymphocytic leukemia (B-CLL). They suggest that dysregulated, continuous high expression of IL-5 in SLE-prone mice may directly or indirectly mediate a skewed signaling of proliferation/differentiation of self-antigen-activated B1 cells, leading to suppression of autoimmune disease, but instead to aberrant expansion of $\mathrm{B} 1$ cells, giving rise to
B-CLL. Down regulation of Th1 cytokines in IL-5 transgenic mice is unclear.

(7) IL-12-Expressing Plasmid DNA. Hagiwara et al. [77] have reported the therapeutic effects of IL-12-encoding plasmid, depending on the concept that lupu is Th2 disease. Thus, they aimed paradigm shift from Th2 to Th1 polarized immune reaction for lupus therapy. MRL/MPlpr/lpr mice were treated with IL-12-encoding plasmid DNA intramuscularly (every 4 weeks, starting at 4 weeks of age). This intervention significantly inhibited the accumulation of CD4(-)CD8(-) double negative T cells reducing lymphadenopathy and splenomegaly. A significant decrease in serum IgG anti-DNA autoantibody titers with a reduction in the proteinuria and glomerulonephritis. However, serum IFN- $\gamma$ level was increased. They suggested that the cytokine balance was skewed towards Th1. However, they discussed the mechanism by this therapy is not totally dependent on an IFN- $\gamma$-mediated pathway. It may be that this plasmid also induced the production of regulatory cytokines that counter balanced inflammatory cytokines [78].

\section{[2] Elimination (Neutralization) of Th1 and Th1-Related Cyokines}

(1) IFN- $\gamma$ R/Fc-Expressing Plasmid DNA. Ozmen et al. [79] have reported that mouse soluble IFN- $\gamma$ receptor (IFN- $\gamma$ R) prevented the onset of glomerulonephritis in $\mathrm{B} / \mathrm{WF}_{1}$ mice.

Lawson et al. [80] have attempted to eliminate (neutralize) IFN- $\gamma$ in mouse lupus models using soluble recombinant IFN- $\gamma$ R. Intramuscular injections of plasmids with cDNA encoding IFN $-\gamma \mathrm{R} / \mathrm{Fc}$ can retard lupus development and progression in MRL-Fas(lpr) mice even though when this treatment was initiated at advanced stage. Theraphy significantly reduced serum levels of IFN- $\gamma$ as well as disease manifestations (autoantibodies, lymphoid hyperplasia, glomerulonephritis, and mortality), when treatment was initiated at the predisease stage. On the other hand, there were no changes in mRNA expression levels from splenic cells for IFN- $\gamma$, IL-2, IL-4, IL-10, IL-12, and TNF$\alpha$ with the exception of twofold increase. This therapy makes application of this nonviral gene therapy in humans with lupus and perhaps other autoimmune/inflammatory conditions, since this method seems to be nontoxic and safe with long-term expression. They postulated that a major effect of IFN- $\gamma$ blockade would be due to downregulation of MHC expression, although it is very difficult to define the exact mechanism(s) by which this cytokine, which has highly pleiotropic properties, promotes autoimmunity. In addition to elimination inflammatory cytokines such as IL1 and TNF- $\alpha$ other than IFN- $\gamma$ [80], administration of cDNA encoding soluble TNF- $\alpha$ receptors, or IL-1 receptor antagonist (IL-1ra), protects against lupus [12, 81].

(2) IL-18 cDNA Vaccination. Bossù et al. [82] have reported protective effects of IL-18 cDNA vaccination on lupus. Their idea elicited a specific anti-IL-18 antibody response by reducing the activity of endogenous IL-18, which is an inducer of IFN- $\gamma$ in T lymphocytes and NK cells, in 
MRL/Mp-Tnfrsf6lpr (lpr) mice closely resembling human SLE. Young lpr mice were vaccinated against autologous IL18 by repeated intramuscular injection of a cDNA coding for the murine IL-18 precursor. Vaccinated mice produced autoantibodies in sera to murine IL-18, and they exhibited a significant reduction in spontaneous lymphoproliferation and IFN- $\gamma$ production as well as less glomerulonephritis and renal damage. Moreover, mortality was significantly delayed in anti-IL-18-vaccinated mice. These studies support the notion that IL-18 plays a major role in the pathogenesis of the autoimmune syndrome of lpr mice and that a reduction in IL-18 activity could be a therapeutic strategy in autoimmune diseases.

However, the exact role of the IL-18 cDNA vaccination in prevention is unclear.

(3) IL-12- and IL-18-Encoding Plasmids. Given the facts that injection of recombinant IL-12 or IL-18 proteins in lpr mice worsened the lupus-like disease [83, 84], and elevated IL-12 and IL-18 serum levels were found in SLE patients $[85,86]$. Neumann et al. [87] have reported that MRL/Mp-Tnfrsf6(lpr) (lpr) mice with increase in both TNF$\alpha$ and IFN $-\gamma$ serum concentrations in age, model for human SLE, were injected intramascularly with plasmids encoding IL-12 and IL-18, either alone or in combination. Five biweekly injections of combined plasmids starting at 4-5 weeks of age diminished serum levels of TNF- $\alpha$ and reduced an ability of lymphocytes from treated mice to produce IFN- $\gamma$ in vitro. Injection of both plasmids synergistically attenuated the development of autoimmune syndromes, lymphoproliferation in secondary lymphoid organs, proteinuria and kidney damage, and pneumonitis. Also, IL-12/IL18 cDNA treatment reduced serum TNF- $\alpha$ concentrations. The constitutively enhanced serum TNF- $\alpha$ level in lpr mice decreased more efficiently by the injection of both cDNAs encoding IL-12 and IL-18 when compared with the single injection.

Lymph node cells from IL-12/IL-18-treated mice produced less IFN- $\gamma$ after in vitro stimulation, and IL-12/IL18 cDNA treatment does not affect anti-dsDNA IgG levels. Regarding the possibly reduced IFN- $\gamma$ generation, the alterations might be due to either the specific elimination of IFN$\gamma$ producing T lymphocytes or NK cells from the whole-cell population, or due to their reduced capability to produce IFN- $\gamma$, if they persist.

They discussed the cDNA injection procedure presumably inducing anti-IL-12 and anti-IL-18 activities although direct evidences are not obtained. They concluded that IL-12 and IL-18 synergistically affect the pathogenesis of the Th1dependent autoimmune syndrome of lpr mice and that both IL-12 and IL-18 may be a therapeutic option in the treatment of autoimmune SLE.

\section{[3] Suppression of Th1, Th2, and \\ Other Immunocompetent Cells}

(1) TGF- $\beta$-Expressing Plasmid DNA or IL-2-Expressing Plasmid DNA. The therapy focusing on wide suppression of immunocompetent cell has been reported by Raz et al.
[88]. MRL/lpr/lpr mice monthly injected intramuscularly with plasmids cDNA expression vectors encoding for TGF $\beta$ or IL-2. Injections (between 6 and 26 weeks) significantly elevated the serum levels of TGF- $\beta$ and IL- 2 compared with a control plasmid without insert. TGF- $\beta$ encoding plasmid had beneficial effects in murine SLE with a prolonged survival of $70 \%$ at 26 weeks compared with $40 \%$ in the control group, decreased antichromatin and rheumatoid factor antibodies and a $50 \%$ decrease in total $\operatorname{IgG}$ production. Renal function was improved with reduced blood urine nitrogen (BUN) levels and kidney inflammation. Those beneficial effects occurred in apparent absence of local or systemic side effects. These effects by TGF- $\beta$-expressing plasmid DNA may be due to suppressed function of CD4(Th1,Th2), CD8 T,B and macrophages. In contrast, IL-2 cDNA injections appeared harmful with a decreased survival to $20 \%$ at 26 weeks (survival rate of nontreated control mice: $40 \%$ at 26 weeks), enhanced total IgG synthesis and autoantibodies production with 4.5 -fold increase in antichromatin antibodies. They concluded that somatic gene therapy may provide simple, inexpensive and effective therapies for the long-term control of autoimmune diseases by TGF- $\beta$-expressing plasmid DNA.

Huggins et al. [89] also investigated the effects of IL2 and TGF- $\beta$ gene therapy in MRL lpr/lpr mice with a different approach. The mice were treated orally with a nonpathogenic strain of Salmonella typhimirium bearing the aroA-aroD-mutations and carrying the murine genes encoding IL- 2 and TGF- $\beta$. TGF- $\beta$ gene therapy produced no improvement in pathology and generally had opposite effects to those of IL-2. IL-2 gene therapy restored the defective T-lymphocyte proliferative response to mitogen and suppressed the autoantibody response, nephritis, and growth of lymphoid tumours.

The reasons of these differences are unclear. Mageed and Prud'homme [78] suggested that it is unclear to what extent the cytokines enter lymphoid tissues and/or the circulation, and how immunological effects are mediated. Therefore, these results must be interpreted with caution, and are difficult to compare with those obtained by other methods of delivery. Thus, they claimed these contradictory results highlight the risks inherency in using cytokines as therapeutic molecules.

\section{[4] Normalization of T Cell Population}

(1) IL-2/Vaccinia Recombinant Virus. Gutierrez-Ramos et al. [90] tried lupus therapy in MRL/lpr mice by altering abnormal T-cell population to normal T-cell population, since the intrinsic abnormality of $\mathrm{T}$ cells in this mouse strain (defect in IL-2 production appears at 4-6 weeks of age in MRL lpr/lpr and $\mathrm{BXSB}$ mice, and somewhat later in the $\mathrm{B} / \mathrm{WF}_{1}$ mouse and becomes more pronounced with disease progression [78]. Mice-vaccinated intraperitoneally with live vaccinia recombinant viruses expressing the human IL-2 gene showed prolonged survival, decreased autoantibody production and rheumatoid factor titres, marked attenuation of kidney interstitial infiltration and intraglomerular proliferation, as well as clearance of synovial mononuclear infiltrates. Inoculation with the IL-2/vaccinia recombinant virus led, additionally, to 
drastic reduction of the $\mathrm{CD}^{+} \mathrm{CD}^{-} \mathrm{CD} 8^{-}$double-negative T-cell population, and improved thymic differentiation and restoration of normal values of mature cells in peripheral lymphoid organs.

In contrast, IL-2 treatment enhanced the disease as described in section [3]-(1). These opposite data suggest multifunction of IL-2 in vivo or methodological difference including disease process.

\section{[5] Costimulation Blockade}

(1) Anti-CD154 (CD40L) Therapy. Wang et al. [91] determined the immunologic effects of anti-CD154 (CD40L) therapy in the $\mathrm{B} / \mathrm{WF}_{1}$ mouse (20-week-old and 26-weekold) treated with continuous hamster anti-CD154 intraperitoneally biweekly for 6 months. IgG anti-dsDNA antibodies decreased during therapy and disease onset was delayed, but immune tolerance did not occur. During treatment, there was marked depletion of CD19+ cells in the spleen; however, autoreactive IgM-producing B cells could still be detected. In contrast, few IgG anti-dsDNA-secreting B cells were detected. Eight weeks after treatment cessation, the frequency of B cells producing IgG anti-dsDNA antibodies was still decreased in $50 \%$ of the mice, and activation and transition of $\mathrm{T}$ cells from the naive to the memory compartment were blocked. AntiCD154 treatment blocked both class switching and somatic mutation by using the marker gene VHBW-16 and induced a variable period of relative unresponsiveness of IgG antidsDNA-producing B cells, as shown by decreased expression of the CD69 marker and failure to generate spontaneous IgG anti-dsDNA-producing hybridomas. Treated mice mounted an attenuated $\operatorname{IgM}$ response to the hapten oxazolone and produced no IgG antioxazolone antibodies.

Anti-CD154 is a B-cell depleting therapy that affects multiple B-cell subsets. Activation of both B and T cells is prevented during therapy. After treatment cessation, autoreactive B cells progress through a series of activation steps before they become fully competent antibodyproducing cells. Wang et al. have stressed that the general immunosuppression induced during treatment will need to be taken into account when using B-cell depleting regimens in humans.

(2) Adenovirus Vector Expressing CTLA-4/IgG. Takiguchi et al. [92] reported that gene therapy strategy is to prevent the effector T-cell function by blocking costimulation, because involving Th1 and Th2 cytokines in lupus pathogenesis suggests the difficulty to target specific cytokines. They demonstrated protective effects of adenovirus vector containing CTLA4IgG, which binds to B7 molecules and inhibits B-cell differentiation to plasma cells, gene (Adex1CACTLA4IgG:AdCTLA4IgG) delivery on the development of lupus nephritis, in MRL/lpr mice. It was demonstrated that a single administration of intravenous injection of AdCTLA4IgG into MRL/lpr mice resulted in almost complete amelioration of lupus nephritis. However, side effects such as increased susceptibility to pathogen due to reduced general immune reaction by this treatment are unclear.
Mihara et al. [93] also reported that Ad-CTLA4Ig, which blocks the B7/CD28 pathway, prevents the onset of disease in B/WF1 mice treated at the age of 20-22 weeks with a single intravenous injection of high dose $\left(2 \times 10^{9} \mathrm{pfu}\right)$. This effect is associated with decreased expansion of both the IgM and IgG autoreactive B-cell population, inhibition of immunoglobulin class switching, and a marked decrease in the numbers of activated $\mathrm{CD} 4^{+} \mathrm{T}$ cells. In contrast, intrinsic $\mathrm{B}$-cell hyperreactivity and the survival of plasma cells in the bone marrow, both of which are less dependent on T-cell help, appear to be unaffected by CTLA4Ig. Administrated Ad-CTLA4Ig existed in the serum for a long time and an immune response to the adenoviral vector was absent. More importantly they showed that CTLA4Ig did not induce a permanent state of tolerance in $\mathrm{B} / \mathrm{WF}_{1}$ mice.

(3) (AAV8)-CTLA-4/Ig and AAV8-CD40/Ig. Ye et al. [94] investigated the potency of costimulatory blockade with adeno-associated virus- (AAV)-mediated gene transfer in prevention and reversal of lupus in a murine model. AAV vectors expressing CTLA-4Ig or CD40Ig were injected into intraperitoneally NZB/NZW mice. A single injection of AAV serotype 8 (AAV8)-CTLA-4Ig in neonatal $\mathrm{B} / \mathrm{WF}_{1}$ mice before the onset of lupus effectively delayed and inhibited autoantibody production, proteinuria, and kidney damage and prolonged their lifespan. In addition, coinjection of AAV8-CTLA-4Ig and AAV8-CD40Ig vectors into neonatal mice achieved the synergistic effect and the best efficacy. The preventive effects were attributed to the suppression of $\mathrm{CD}^{+}{ }^{+} \mathrm{T}$-cell activation and the transition from naive to memory $\mathrm{T}$ cells. Moreover, coinjection of these $2 \mathrm{vec}-$ tors in adult mice reversed existing autoantibody levels, suppressed the development of proteinuria, and prolonged their lifespan. The therapeutic effects were found to be dependent on the vector dose. Moreover, long-term, highlevel costimulatory blockade transgene expression does not completely suppress the host humoral immune response to KLH, a T-cell-dependent antigen. AAV-mediated long-term gene expression did not severely suppress the host humoral response to foreign antigen. They showed that delivery of costimulatory inhibitor transgenes by AAV vectors could prevent and reverse lupus in this murine model, suggesting the potential of AAV-mediated gene transfer as an alternative treatment for lupus, since it did not completely suppress the host humoral response to foreign antigens.

(4) Adenovirus Vector Expressing PD-L1 Gene with Anti-B7h $m A b$. Deliberate delivering of negative costimulation to halt unwanted T- and B-cell activation has been tested by Ding et al. [95], although blocking positive T-cell costimulation has shown effectiveness in preventing the onset of murine lupus as shown in sections [5]-(1) and [5]-(2). They focused on enhancing PD-1 signaling because unlike CTLA-4, PD1 is more broadly induced on not only $\mathrm{T}$, but also $\mathrm{B}$ and myeloid cells after activation [96]. PD-L1 (also called B7$\mathrm{H1}$ ) is one of the ligands of this novel immunoinhibitory receptor [97]. Engaging PD-1 by PD-L1 could inhibit the activation of both $\mathrm{T}$ and $\mathrm{B}$ cells $[98,99]$. They constructed an adenovirus containing the full-length mouse PD-L1 gene 
(Ad.PD-L1), and tested its efficacy alone and together with an anti-B7h (inducible costimulator ligand, B7 homologous protein (B7h) called as ICOS-L [100]) mAb to block ICOS, a new member of the CD28 family of costimulatory molecules that is induced on $\mathrm{T}$ cells after activation, and regulates T-cell-dependent humoral immune responses [101, 102], in preventing lupus nephritis in BXSB mice, which spontaneously develop an autoimmune syndrome characterized by hypergammaglobulinemia, autoantibody production, and development of fatal glomerulonephritis that closely resembles SLE in humans. This combined therapy in mice with intravenous injection dramatically delayed the onset of proteinuria, effectively inhibited IgG autoantibody production, and significantly reduced hypercellularity and deposition of IgG in glomeruli, resulting in almost complete amelioration of lupus nephritis in these animals. Their results indicate the therapeutic potential of simultaneous stimulation of PD-1mediated pathway and blockade of ICOS-B7h costimulation in the prevention of human lupus nephritis, suggesting the benefits of shifting the balance of positive versus negative costimulation on effector $\mathrm{T}$ cells in ongoing autoimmune diseases.

\section{[6] Blys Blockade}

(1) Adenovirus Vector Expressing Transmembrane Activator and CAML Interactor Receptor (TACI). Liu et al. [103] examined the effect of BLyS blockade in 3 animal models of lupus depending on the evidences that serum BLyS (also known as TALL-1, THANK, zTNF4, and BAFF) is increased in autoimmune diseases, both in animal models and in humans. Antibodies and lupus-like disease manifestations were examined in mice after administration of a single intravenous injection of an adenoviral construct for transmembrane activator and CAML interactor receptor (AdTACI) that produces high serum levels of TACI-Fc fusion protein. In C57BL/6 (B6) lpr/lpr mice (B6.lpr/lpr), which were used to model of autoimmunity in absence of severe disease, treatment of younger mice with AdTACI prevented the development of hypergammaglobulinemia. In contrast, use of AdTACI for BLyS blockade had only transient effects on the levels of IgG in normal B6 mice. AdTACI blocked the development of autoantibodies in younger B6.lpr/lpr mice and reversed the production of autoantibodies in older B6.lpr/lpr mice, and also reduced the numbers of splenic plasma cells. In MRL.lpr/lpr mice, which were used to examine disease manifestations, AdTACI reduced the extent of glomerulonephritis and proteinuria and improved survival, but had little effect on T-cell infiltration and interstitial nephritis. However, in $\mathrm{BW} / \mathrm{F}_{1}$ mice, AdTACI induced neutralizing anti-TACI antibodies and failed to reduce the numbers of B cells. BLyS blockade has little effect on IgG levels in normal mice, but reverses the production of spontaneously produced IgM and IgG autoantibodies in setting of established autoimmunity. Blockade of BLyS ameliorates B-cell-dependent disease manifestations even in the MRL.lpr/lpr model, but its effectiveness on autonomous T-cell aspects of the disease is limited. Moreover, its effectiveness is neutralized by anti-TACI antibodies when it is present.
These results provide a basis for understanding the potential effects of BLyS blockade in human disease.

\section{[7] Suppression of Nephritic Kidney Inflammation}

(1) Adenovirus Vector Expressing T $\beta$-ExR. Haviv et al. [104] have reported that systemic adenoviral (Ad) gene therapy for renal disorder in the context of blocking renal fibrosis by AdTbeta-ExR, which encodes a chimeric soluble molecule comprising the entire ectodomain of the human type II TGF- $\beta$ receptor, genetically fused to the Fc fragment of the human IgG1 (sTbetaRII), and AdCAT $\beta$ $\mathrm{TR}$, which encodes only the dominant-negative truncated ectodomain of the human type II TGF- $\beta$ receptor, intramuscularly in MRL/MpJTnfrsf6lpr mice, which are homozygous for the FAS-protein receptor (lpr, lymphoproliferation) spontaneous mutation (Tnfrsf6lpr) and develop systemic autoimmunity and ICs-mediated glomerulonephritis. This therapy focussed on suppression of kidney inflammation using recombinant adenoviral (Ad) vectors holding many advantages, such as infection of a wide range of quiescent renal cells and the potential for organ targeting employing genetic or antibody conjugation strategies TGF type II receptor (AdT-ExR) to block TGF- $\beta$, a cytokine playing a key role in fibroproliferative renal disorders and TGF- $\beta$, is a key regulator of production, degradation, and accumulation of extracellular matrix.

The onset of the autoimmune disease is at about 8 weeks of age and females die earlier than males, thereby resembling systemic lupus erythematosus-like autoimmune syndromes. sTbetaRII was detected in the glomeruli after remote i.m. injection of AdTbeta-ExR, but not the control AdCAT $\beta$ $\mathrm{TR}$, indicating renal deposition of the heterologous soluble fusion protein after its expression in the muscle and secretion into the circulation. AdTbeta-ExR, but not AdCATbeta-TR, could transiently inhibit mesangial expansion, glomerular hypercellularity, proteinuria, and cortical interstitial fibrosis. However, amelioration of renal disease in CXCR3-/MRL/lpr mice therefore seems to be more a result of an impaired cellular immune response, rather than an impaired humoral immune response.

[II] Balance Shift from Immunogenic to Tolerogenic Dendritic Cells (DCs)

[1] Immunogenic DCs Determine Lupus. It is well known that viral infections, in general, trigger unabated production of IFN $-\alpha / \beta$. SLE patients have long been known to display elevated levels of type I interferon (IFN $\alpha / \beta)$ in their serum [105], but there are a few attention on the role of IFN $\alpha / \beta$ compared to other cytokines in lupus pathogenesis. Pascual et al. [105] proposed in 2001 that an excess IFN $\alpha / \beta$ might break peripheral tolerance through the activation of myeloid dendritic cells (mDCs). And since then, accumulating evidences suggest causal roles of IFN $\alpha / \beta$ pathway (i.e., human plasma cell differentiation and activation of CD8 T cells) in human SLE.

It has also become evident that antigen-antibody complexes (ICs) containing RNA and DNA activate DCs and B 
cells through interaction with $\mathrm{F} c \gamma \mathrm{R}$ and Toll-like receptor (TLRs) 7, 8, and 9, respectively [85]. Thus, lupus-specific autoantigens might act as TLR ligands and contribute to IFN $\alpha / \beta$ and autoantibody production.

Horwitz [106] proposed in his review that an important goal in the management of human SLE is to restore the DCs together with regulatory $\mathrm{T}$ (Treg) cells [107], since once the DC balance has been shifted back to tolerogenic predominance, further stimulation of these tolerogenic DCs with peptide autoantigens should expand or induce new inducible (i)Tregs.

(1) Restoration of $D C$ s and $I F N \alpha / \beta$. There are two main DC differentiation pathways [108]: mDCs and plasmacytoid DCs (pDCs) [109]. Resident mDCs that encounter bacteria at mucosal surfaces or at sites of tissue damage migrate to the lymph node via afferent lymphatics. Importantly, $\mathrm{mDC}$ express receptors, such as TLRs, nucleotide binding oligomerization domain (NOD) proteins, and lectins, to capture these pathogens. Mouse mDCs express TLR7 and TLR9 whereas human mDCs lack TLR7, but express TLR7 upon exposure to IFN- $\alpha / \beta[110]$. mDCs can also be activated by immune complexes (ICs) through activating Fc $\gamma$ RIIa $[111,112]$.

Pascual et al. [105] have reviewed that increased IFN$\alpha / \beta$ induces the activation of immature mDCs that control peripheral tolerance by deleting autoreactive lymphocytes. IFN $-\alpha / \beta$ secreted from matured DCs activate and expand autoreactive $\mathrm{T}$ cells, both helping autoreactive B-cell development directly, and IFN- $\alpha / \beta$ also indirectly allows the expansion and survival of $\mathrm{CD}^{+}$and $\mathrm{CD}^{+} \mathrm{T}$ cells as well as the differentiation of $\mathrm{B}$ cells into plasma cells. Additionally the capture of apoptotic cells by $\mathrm{mDCs}$ and nucleic acid-containing ICs by pDCs and autoreactive B cells broadens the autoimmune reaction, thereby leading to disease manifestations.

pDCs circulate in the blood and lymphoid organs and by viral infection, these cells secrete large amounts of IFN- $\alpha / \beta$ as well as other cytokines [109]. They also differentiate into cells with DC morphology and function [113]. Both mouse and human pDCs express TLR7 and TLR9 and chromatin-containing and snRNPs-containing ICs are internalized by pDCs via Fc $\gamma$ RIIa and reach the endosomal compartment where they activate TLR7 and TLR, respectively, leading to secretion of cytokines such as IFN$\alpha / \beta$ [26]. (The classic lupus autoantigens snRNPs can also be directly internalized within endosomes where they stimulate TLR7 and TLR8 [114].) Banchereau and Pascual [26] have demonstrated that ICs are formed when autoantibodies are engaged with either (1) chromatin whose DNA can interact with TLR9 inside pDC and B-cell endosomes or (2) ribonucleoproteins whose RNA can interact with TLR7 also inside $\mathrm{pDC}$ and $\mathrm{B}$-cell endosomes. TLR signaling in $\mathrm{pDC}$ results in the secretion of IFN- $\alpha / \beta$ and IL- 6 . The combined triggering of the autoreactive BCR and TLR results in autoreactive B cell proliferation, and IFN- $\alpha / \beta$ induces their differentiation into plasmablasts, and IL6 induces their differentiation into autoantibody-secreting plasma cells.
Mathian et al. [9] confirmed the critical role of IFN$\alpha / \beta$ in SLE pathogenesis. In vivo delivery of IFN $-\alpha / \beta$ to preautoimmune $\mathrm{B} / \mathrm{WF}_{1}$ mice rapidly results in severe SLE. dsDNA antibodies appear as early as 10 days after initiation of IFN- $\alpha$ treatment, demonstrating a critical role for IFN$\alpha$ in the selection and expansion of autoreactive clones. Proteinuria and glomerulonephritis-induced death occurred in all treated mice at 9 and 18 weeks, respectively, a time when untreated mice did not show any sign of disease. Banchereau and Pascual [26] reported that the cytokines yield distinct DC subsets that might lead to distinct immunopathologies. Immature DCs exposed to IFN $-\alpha / \beta$ or TNF- $\alpha$ will yield distinct DC subsets that will uniquely polarize naive $\mathrm{T}$ cells through the expression of different cytokines and costimulatory molecules. They proposed the new concept that mutual inhibitory effects of TNF- $\alpha /$ IFN- $\alpha / \beta$, which determine the direction of diseases like the mutual inhibitory effects of Th1/Th2, which is proposed by concept of Monneaux and Muller [5]. For example, excess TNF- $\alpha$ production from immature DCs inhibits IFN- $\alpha / \beta$ production from immature DCs, leading to inhibition of the development of lupus. On the other hand, IFN $-\alpha / \beta$ polalized immunity lead to lupus, by suppressing the production of TNF- $\alpha$.

(2) Prevention by TNF. Gill et al. [115] found high amounts of soluble TNF- $\alpha$ receptors and IFN- $\alpha / \beta$ found in SLE patients. Jacob and McDevit [116] observed that soluble bioactive TNF- $\alpha$ prevent lupus in B/WF1 mice, which bear a genetic deficiency in TNF- $\alpha$. These evidences suggest that TNF-mediated downregulation of the IFN $-\alpha / \beta$ pathway in therapy. However, the application of TNF- $\alpha$ remains unclear, since TNF-mediated downregulation of the IFN $-\alpha / \beta$ pathway is largely unknown.

\section{[2] Treg Cells and DCs}

(1) Regulatory T(Treg) Cells. Horwitz [106] proposed in his review that restoration of the balance between immunogenic and tolerogenic DCs with correction of Treg numbers and function is an important goal in the management of human SLE, although still unsolved issues remain.

Toubi [117] reported that $\mathrm{CD} 4^{+} \mathrm{CD} 25^{+}$Treg cells play a role in autoimmune diseases in human. Restoration of regulatory $\mathrm{T}$ (Treg) cell numbers and functions in individuals with SLE has the potential to lead to remission of SLE by shifting back to tolerogenic predominance in vivo [106]. This new strategy to normalize Treg function is expected to be ideal therapy not only in SLE but also other autoimmune disease including allergic diseases, which are typical Th2 diseases, although it is not conclusive [118]. Depletion of $\mathrm{CD}^{+} \mathrm{CD} 25^{+}$cells in $\mathrm{B} / \mathrm{WF}_{1}$ hybrid mice accelerated the onset of glomerulonephritis [119] and sialoadenitis [120].

$$
\mathrm{CD} 4^{+} \mathrm{CD} 25^{+} \text {natural or thymus-derived }
$$
$\mathrm{CD}^{+} \mathrm{CD} 25^{+} \mathrm{Foxp}^{+}$cells are decreased in young $\mathrm{B} / \mathrm{WF}_{1}$ and/or $\mathrm{SNF}_{1}$ mice before they develop glomerulonephritis and adoptive transfer of $\mathrm{CD} 4^{+} \mathrm{CD} 25^{+}$cells from young lupus-prone mice have some protective effects on the development of the disease [121]. 
However, the evidence that Treg defects play a major role in the perpetuation of this disease is only suggestive in human [106]. Also, regulatory/suppressor T cells (Tregs) consisted of heterogeneous populations of CD4 cells, CD8 cells, and even natural killer T cells [122], and approximately $5 \%$ of CD $4^{+}$cells in the mouse are Tregs that express Foxp3, whereas only $1 \%-2 \%$ of the total $\mathrm{CD}^{+} \mathrm{T}$-cell population of $\mathrm{CD}^{+}$cells express Foxp3 in humans $[106,123]$. Thus Horwitz [106] pointed out that the cytokine and gene expression profile of Foxp $3^{+}$Tregs in SLE in comparison with healthy subjects has yet to be defined. Also, studies of Tregs in SLE are mostly limited to blood lymphocytes and there are controversy evidences that decrease in $\mathrm{CD} 4{ }^{+} \mathrm{CD} 25$ high cells in some reports whereas there are no decrease in those cells.

Moreover, IL-2 and TGF- $\beta$ can convert naïve $\mathrm{CD} 4{ }^{+} \mathrm{CD} 25^{-} \mathrm{T}$ cells to $\mathrm{CD} 25^{+} \mathrm{Foxp}^{+}$suppressor cells in mice, and Tregs-induced ex vivo with IL- 2 and TGF- $\beta$ have protective lupus-like syndromes in mice $[22,124]$, but similar conversion in humans is more complex and another problem with measurements of Tregs in humans is that the numbers circulating in the blood may not correlate with the numbers and function of these cells in the tissues, and there is very limited information concerning Foxp $3^{+}$Treg numbers in lymphoid organs and in tissues of patients with SLE [106].

In both mice and humans, $\mathrm{CD} 4^{+} \mathrm{CD} 25^{+} \mathrm{Foxp}^{+} \mathrm{T}$ cells (iTreg) themselves differentiate into Th17 cells in the presence of IL-6 (and in the absence of exogenous TGF- $\beta$ ), indicating that $\mathrm{CD} 4^{+} \mathrm{CD} 25^{+} \mathrm{Foxp} 3^{+}$regulatory $\mathrm{T}$ cells can function as inducers of Th17 cells and can differentiate into Th17 cells in both mice and human $[125,126]$. Zheng et al. [124] found that IL-2 and TGF- $\beta$ downregulate IL6 receptor expression and IL- 6 signaling. The resistance of iTregs to Th17 conversion suggests that they can function more effectively than nTregs in the central role of IL2 in combination with TGF- $\beta$ to maintain immunologic homeostasis in autoimmune diseases [127]. However, this has yet to be demonstrated in human [106]. Moreover, the principal target of Treg activity is probably antigenpresenting DCs rather than T cells $[128,129]$. In addition, Tregs may have direct suppressive effects on B cells [130], on natural killer cells [131] in mice. The contact-dependent mechanism of action of $\mathrm{CD}^{+}{ }^{+} \mathrm{Foxp}^{+}{ }^{+}$Tregs also remains poorly understood [31].

(2) Interactions between Tolerogenic DCs and Treg Cells. Min et al. [132] demonstrated that besides controlling the activity of other $\mathrm{T}$ cells and $\mathrm{B}$ cells, evidence has been obtained that Tregs also induce tolerogenic DCs in transplant tolerance in the $\mathrm{C} 57 \mathrm{BL} / 6>\mathrm{BALB} / \mathrm{c}$ cardiac allograft model using simultaneously targeting $\mathrm{T}$ cell and $\mathrm{DC}$ function using anti-CD45RB mAB (CD45 is a single chain glycoprotein expressed on hemopoietic cells such as T cells, and members of the CD45 family of transmembrane protein tyrosine phosphatases are critically involved in lymphocyte activation.) and LF 15-0195, a novel analog of the antirejection drug 15-deoxyspergualin, respectively. Moteober, LF inhibits DC and anti-CD45RB mAb inhibits T-cell responses in vitro. They concluded that tolerance induction is associated with a self-maintaining regulatory loop in which tolerogenic DCs induce the generation of Treg cells from naive T cells and Treg cells programs the generation of tolerogenic DCs from DCs progenitors.

(3) Tolerogenic Peptide. Kang et al. [27] reported that splenic dendritic cells (DCs) captured the subcutaneously injected low-dose peptide (three times with $\mathrm{H} 4$ (71-94) peptide $(1 \mu \mathrm{g} /$ mouse $)$ in every $2 \mathrm{wk}$.$) , which is autoepitope for$ lupus nephritis-inducing Th cells in murine and human lupus and shows cross-reactively recognized by autoimmune Th cells and B cells, rapidly and expressed a tolerogenic phenotype in lupus-prone 12 -week-old female $\mathrm{SNF}_{1}$ hybrids but prenephritic. The DC of the tolerized animal, especially pDC, produced increased amounts of TGF- $\beta$, but diminished IL- 6 on stimulation via the TLR-9 pathway by nucleosome autoantigen and other ligands; those pDC blocked lupus autoimmune disease by simultaneously inducing autoantigen-specific Treg and suppressing inflammatory Th17 cells that infiltrated the kidneys of untreated lupus mice. Thus, the H4 (71-94) peptide tolerance therapy that preferentially targets pathogenic autoimmune cells could spare lupus patients from chronically receiving toxic agents or global immunosuppressants and maintain remission by restoring autoantigen-specific Treg cells.

\section{Future of Balance Shift of Th1 (IFN- $\gamma$ )/Th2 (IL-4) and Immunogenic DCs $($ IFN- $\alpha / \beta) /$ Tolerogenic DCs (TNF- $\alpha$ )}

There are two main streams of this review in terms of balance shit from [I] Th1 to Th2 cells and from [II] immunogenic $($ IFN- $\alpha / \beta)$ to tolerogenic (TNF- $\alpha$ ) DCs, but the former seems to be more realistic.

[I] Therapy by Th1/Th2 Balance Shift for Clinical Use. Main issues of this review is balance shift from Th1 to Th2 or alteration of Th1/Th2 ratio by targeting IFN- $\gamma$, but not costimulation blockade. For this purpose, gene therapy seems to be suitable compared to bioactive cytokines or antibodies against cytokines.

The number of naked/plasmid DNA (18.3\%), adenovirus $(24.9 \%)$ and retrovirus $(21.7 \%)$ studies has dramatically increased among all gene therapy in clinical trials (www.wiley.co.uk/genmed/clinical, 2007) [133]. Additionally, the coverage of indications targeted in preclinical and clinical studies using plasmid DNA is broad-covering cancer, infectious and noninfectious diseases in both the prophylactic vaccine setting as well as a therapeutic setting. The nonviral plasmid DNA approach is particularly attractive due to safety, versatility, and ease of preparation [88]. Also, compared to viral vectors, it has the benefit of not inducing immunogenic reactions against components of the vector itself upon administration to patients [134]. This process can be adapted by other academic centers for human or large animal clinical trials with cost-effectiveness [135].

Gene transfer offers numerous advantages for the in vivo delivery of cytokines or their receptors for immunotherapeutic use [136-138]. Actually, there are a lot of trial 


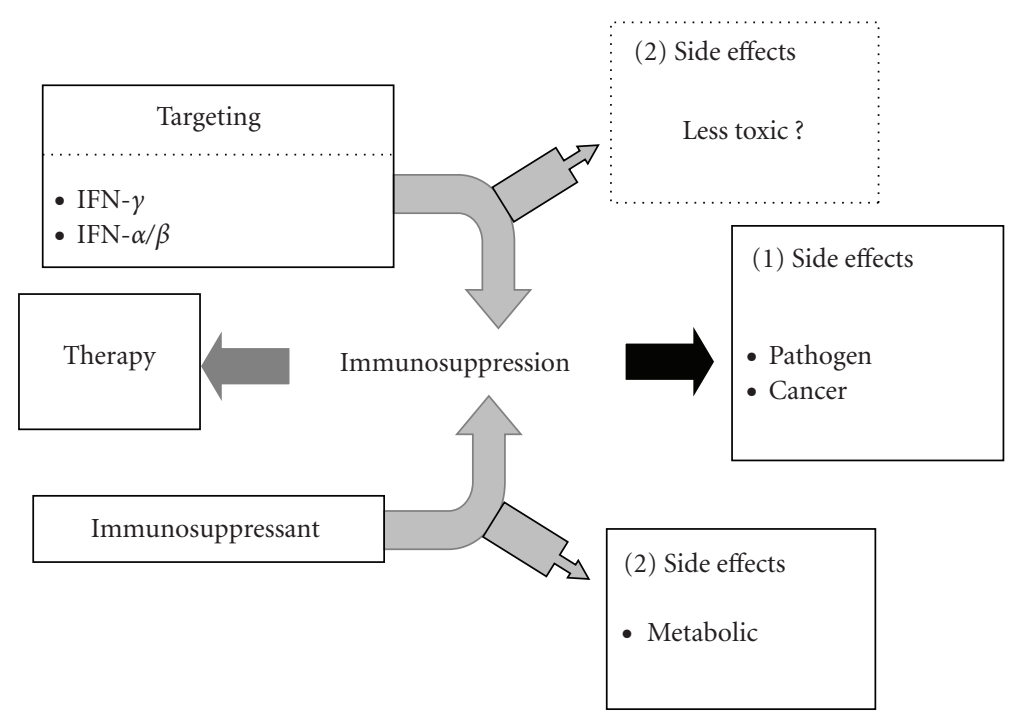

FIGURE 5: Cytokine targeted therapy will be expected to clinical application, but more detailed examination of side effects (e.g., development of infections, cancer, allergic diseases, and autoimmunity) is required. Clinical application to lupus must be based on their safety profile, adverse effects, risks, and advantages. Likewise, in this analysis we offer specific recommendations, based on evidence, for the best, is Th1/TH2 balance shift in vivo by using IL-4 gene therapy.

of gene therapy in other autoimmune diseases (e.g., T1D, rheumatoid arthritis: RA) in model animals and in human with RA [139]. The first human trial for RA began in 1996 [140]. Clinical trials for RA have been initiated (phase II). The first evidence of possible clinical responses to gene transfer was published in 2008 [141]. Plasmid DNA is superior to viral vectors for direct gene transfer into adult mouse skeletal muscle [142].

Still in the experimental phase, gene therapy in lupus promises to correct the aberrant immunological response without the numerous side effects of the currently used immunosuppressant medications in lupus [143] (Figure 5 and Table 1). Some study indicated undesirable side effects such as the impaired response to T-cell-depend and T-cellindependent antigens, increased susceptibility for infectious diseases. In addition, IL-5 suppresses lupus nephritis, but it promotes B-cell lymphoma later. Moreover, IL-4 and IL5 may have a possibility to increase susceptibility to Th2 diseases (e.g., allergic rhinitis, asthma). Thus, despite its promise, gene therapy is a young field and a variety of questions must be addressed in lupus [78]. These points are needed to clarify.

[II] Therapy by Induction of Tolerogenic DCs for Clinical Use. Banchereau and Pascual [26] have proposed an extension of the Th1-Th2 (inflammation-allergy) paradigm [110], which integrates autoimmune responses, by two sets of opposite vectors, that is, TNF- $\alpha$-IFN- $\alpha / \beta$ and IL- 4 -IFN- $\gamma$. The sum of the cytokines yields an equilibrium point, which allows protective immunity when cytokines are equal. This dynamic system can accommodate the prevalence of either cytokine to a certain extent. However, when one of the cytokines prevails beyond a certain threshold, the equilibrium point moves into a zone of immunopathology, such as autoimmunity, allergy, or inflammation. Thus, when the TNF prevails, TNF$\alpha$-mediated autoimmunity such as arthritis will occur. When the IFN- $\alpha / \beta$ vector prevails, IFN autoimmunity such as SLE will occur. This might be due to increased bioavailability of one cytokine or decreased bioavailability of the other one. The unabated production of a given cytokine will affect the cells of the immune system and most particularly DCs. Thus, IFN- $\alpha / \beta$-stimulated DCs will polarize naive $\mathrm{T}$ cells differently than TNF-stimulated DCs.

Also, Banchereau and Pascual [26] claimed that the basic genetic alterations leading to IFN $-\alpha / \beta$ overproduction and $\mathrm{B}$ cell tolerance breakdown in SLE and establishment of the role of other cells like neutrophils, TFh cells, and $\operatorname{Tr} 1$ cells in the pathogenesis of human SLE for new avenues of treatment. Whether, like TNF antagonists, which have brought considerable relief to RA patients, IFN antagonists will bring relief to SLE patient. Blocking of IFN $\alpha / \beta$ (antagonists, balance shift by TNF) including their side effects and safety is largely unknown.

\section{Conclusions}

Simple, effective,easy and safe methods with less side effects in vivo may be required for preventive intervention.

(1) Cytokine-targeted gene therapy can be applied to clinical use as suggested by Piccirillo and Prud'homme [71]. Also this seems to be realistic rather than targeting proinflammatory versus immunosuppressive cytokine profiles. Naked DNA method may be suitable for therapy as shown in Table 1.

(2) Prud'homme suggested that genes encoding TGF$\beta 1$, IL-4, and IL-10 are most frequently protective in lupus [12, 81], but IL-4 expressing plasmid DNA may 
TABLE 1: Several gene therapies in lupus model mice.

\begin{tabular}{|c|c|c|c|c|c|}
\hline & Route & Vector & Model & Effect & mechanism/(evidence) (Reference) \\
\hline \multicolumn{6}{|l|}{ Cytokine } \\
\hline IL-4 & i.p & naked DNA & $\mathrm{B} / \mathrm{WF}_{1}$ & + & Balance shift from Th1 to Th2 [68] \\
\hline IL-2 & i.m. & naked DNA & MRL lpr/lpr & $-*$ & Enhanced autoantibodies production $[88]$ \\
\hline IL-2 & oral & naked DNA & MRL lpr/lpr & + & $\begin{array}{l}\text { Restoration of T cell response, and suppression of } \\
\text { autosntibody response [89] }\end{array}$ \\
\hline IL-2 & i.p. & vaccinia virus & MRL lpr/lpr & + & Normalization of T cell population $[90]$ \\
\hline IL-12 & i.m. & naked DNA & MRL lpr/lpr & + & Cytokine balance skewed towards Th1 [77] \\
\hline TGF- $\beta 1$ & i.m. & naked DNA & MRL lpr/lpr & + & $\begin{array}{l}\text { Suppression of function of CD4 (Th1,Th2), CD8 T, } \\
\text { B and macrophages. [88] }\end{array}$ \\
\hline TGF- $\beta 1$ & oral & naked DNA & MRL lpr/lpr & - & No effect $[89]$ \\
\hline IL-18 & i.m. & naked DNA & MRL lpr/lpr & + & $\begin{array}{l}\text { Elimination of IL-18 by induction of auto-anti-IL-18 } \\
\text { antibody [82] }\end{array}$ \\
\hline IL-12/IL-18 & i.m. & naked DNA & MRL lpr/lpr & + & $\begin{array}{l}\text { Presumably elimination of IL-12/IL-18 induction of } \\
\text { anti-IL-12/IL-18 antibodes [87] }\end{array}$ \\
\hline \multicolumn{6}{|l|}{ Blockade } \\
\hline IFN- $\gamma \mathrm{R} / \mathrm{Fc}^{*}$ & i.m. & naked DNA & MRL lpr/lpr & + & IFN- $\gamma$ blockade $[80]$ \\
\hline CTLA-4/IgG & i.m. & adenovirus & MRL lpr/lpr & + & costimulatory blockade [92] \\
\hline CTLA-4/Ig & i.v. & adenovirus & $\mathrm{B} / \mathrm{WF}_{1}$ & + & costimulatory blockade [93] \\
\hline CTLA-4/CD40 & i.m. & AAV & $\mathrm{B} / \mathrm{WF}_{1}$ & + & costimulatory blockade $[94]$ \\
\hline PD-L1/anti-B7h & i.m. & adenovirus & BXSB & + & Negative costimulatory blockade [95] \\
\hline TACI & i.v. & adenovirus & $\begin{array}{l}\text { B6.lpr/lpr } \\
\text { B/WF }_{1} \\
\text { MRL lpr/lpr }\end{array}$ & $\begin{array}{l}- \\
\pm \\
\pm\end{array}$ & Blys blockade [103] \\
\hline $\mathrm{T} \beta$-ExR & i.v. & adenovirus & $\mathrm{MRL} / \mathrm{MpT}^{\mathrm{Tnfrsf} 6 \mathrm{lpr}}$ & + & TGF- $\beta$ blockade [104] \\
\hline
\end{tabular}

* worsen, \pm : less effective, AAV: adeno-associared virus.

be advantageous compared to other two cytokines as discussed in each section. Also, the major activity of IL-18 is the induction of Th1 cells in the presence of IL-12, and IL-12 without IL-18 has an independent pathway to induce Th1 response [144], suggesting complexity of targeting those cytokines. Blocking of costimulation in antigen presenting process and elimination of B cells including IL-6 are effective, but those therapies may severely compromise immune responsiveness in general.

(3) Van Raalte et al. [4] have reported that despite excellent efficacy in terms of immunosuppression, glucocorticoid (GC) therapy is hampered by their notorious metabolic side effect profile. Thus, current trials to segregate GC's anti-inflammatory and metabolic actions, are currently being developed. Actually, they have reported that despite excellent efficacy in terms of immunosuppression, glucocorticoid therapy is hampered by their notorious metabolic side effect profile. Thus, current trials to segregate GC's antiinflammatory and metabolic actions, are currently being developed. On the other hand, compared to glucocorticoids, cytokine targeted therapy has some merit, since side effects such as increased metabolic action may be less in cytokine therapy. Combination of the use of immunosuppressants and cytokine targeted therapy also seems likely.
(4) Balance shift from immunogenic to tolerogenic DCs by targeting IFN $\alpha / \beta$ together with normalization of Treg cell function in individuals with SLE has the potential to lead to remission of this autoimmune disease. However, there are a few information about the IFN $\alpha / \beta$ therapy and complicated interaction of DCs and Treg cells for balance shift. Moreover, the information of side effects is totally lacking. Thus, further studies are needed to accumulate the information for therapy.

(5) Finally, for the clinical application, we have to remind that the data obtained from model mouse are not simply applicable for human with SLE (species difference). For example, Horwitz [106] has stressed to distinguish human lupus from mouse lupus, since in mice the course of the disease is steadily downhill and fatal whereas human disease is cyclic and characterized by exacerbations and remission. In addition, several murine lupus models other than $\mathrm{B} / \mathrm{WF}_{1}$ exist and they can be divided into spontaneous, congenic, and engineered models as follows [145]. The best known spontaneous models arise on New Zealand Black (NZB), New Zealand White (NZW), MRL, BXSB, and SWR backgrounds. Hybrids of some of these background strains, like the NZB/W $F_{1}, N Z M 2410$, and the SWR/NZB $F_{1}$ develop ANA, glomerulonephritis, and other features 
of human disease. The lpr (Fas) or gld (FasL) mutations on the MRL background give rise to mice with features of human lupus. However, degree of lymphoproliferation that occurs in these mice is not found in humans. Additionally, MRL-lpr/lpr mice spontaneously develop arthritis, and it displays more features of RA than of the arthropathy seen in human SLE. Conversely, humans carrying mutations in the Fas/FasL genes do not develop SLE. The Yaa mutation, which accelerates disease on the BXSB background, is due to a translocation of the TLR7 gene into the Y chromosome, explaining the predominantly male predisposition to disease in this particular model [146, 147], which is at striking difference with the $9: 1$ female to male ratio in human SLE.

\section{Acknowledgments}

This paper was supported, in part, by a grant-in-aid of the Ministry of Education, Science, Sports and Culture of Japan (nos. 15380210, 17658142, and 21580362). Thanks to Miss Junko Hayashi for reading the paper. Permission to reuse Figure 5 is from Nephrol Dialysis Transplant 2007, 22:313138: Systemic administration of interleukin-4 expressing plasmid DNA delays the development of glomerulonephritis and prolongs survival in lupus-prone female $\mathrm{NZBxNZWF}_{1}$ mice, Oxford University Press. Also, the author declares that he has no conflict of interest.

\section{References}

[1] D. M. Klinman and A. D. Steinberg, "Inquiry into murine and human lupus," Immunological Reviews, no. 144, pp. 157193, 1995.

[2] D. Koffler, "Immunopathogenesis of systemic lupus erythematosus," Annual Review of Medicine, vol. 25, pp. 149-164, 1974.

[3] A. Doria and C. Briani, "Lupus: improving long-term prognosis," Lupus, vol. 17, no. 3, pp. 166-170, 2008.

[4] D. H. Van Raalte, D. M. Ouwens, and M. Diamant, "Novel insights into glucocorticoid-mediated diabetogenic effects: towards expansion of therapeutic options?" European Journal of Clinical Investigation, vol. 39, no. 2, pp. 81-93, 2009.

[5] F. Monneaux and S. Muller, "Molecular therapies for systemic lupus erythematosus: clinical trials and future prospects," Arthritis Research \& Therapy, vol. 11, no. 3, article 234, 2009.

[6] Z. Amoura, J. Haroche, and J.-C. Piette, "Systemic lupus erythematosus: future therapeutic avenues," Revue de Medecine Interne, vol. 29, no. 9, pp. 718-724, 2008.

[7] Z. M. Sthoeger, A. Sharabi, Y. Molad et al., "Treatment of lupus patients with a tolerogenic peptide, hCDR1 (Edratide): immunomodulation of gene expression," Journal of Autoimmunity, vol. 33, no. 1, pp. 77-82, 2009.

[8] L. Llorente, Y. Richaud-Patin, C. García-Padilla, et al., "Clinical and biologic effects of anti-interleukin-10 monoclonal antibody administration in systemic lupus erythematosus," Arthritis \& Rheumatism, vol. 43, pp. 1790-1800, 2000.

[9] A. Mathian, A. Weinberg, M. Gallegos, J. Banchereau, and S. Koutouzov, "IFN- $\alpha$ induces early lethal lupus in preautoimmune (New Zealand Black x New Zealand White)F1 but not in BALB/c mice," Journal of Immunology, vol. 174, no. 5, pp. 2499-2506, 2005.

[10] M. K. Crow and K. A. Kirou, "Interferon- $\alpha$ in systemic lupus erythematosus," Current Opinion in Rheumatology, vol. 16, no. 5, pp. 541-547, 2004.

[11] B. K. Finck, B. Chan, and D. Wofsy, "Interleukin 6 promotes murine lupus in NZB/NZW $\mathrm{F}_{1}$ mice," Journal of Clinical Investigation, vol. 94, no. 2, pp. 585-591, 1994.

[12] G. J. Prud'homme, B. R. Lawson, and A. N. Theofilopoulos, "Anticytokine gene therapy of autoimmune diseases," Expert Opinion on Biological Therapy, vol. 1, no. 3, pp. 359-373, 2001.

[13] M. Kunz and S. M. Ibrahim, "Cytokines and cytokine profiles in human autoimmune diseases and animal models of autoimmunity," Mediators of Inflammation, vol. 2009, Article ID 979258, 2009.

[14] C. K. Wong, L. C. W. Lit, L. S. Tam, E. K. M. Li, P. T. Y. Wong, and C. W. K. Lam, "Hyperproduction of IL-23 and IL-17 in patients with systemic lupus erythematosus: implications for Th17-mediated inflammation in auto-immunity," Clinical Immunology, vol. 127, no. 3, pp. 385-393, 2008.

[15] O. M. Steinmetz, J. E. Turner, H. J. Paust et al., "CXCR3 mediates renal Th1 and Th17 immune response in murine lupus nephritis," Journal of Immunology, vol. 183, no. 7, pp. 4693-4704, 2009.

[16] E. Díaz-Jouanen, C. Abud-Mendoza, M. A. Garza-Elizondo, et al., "Grupo de Estudio de Nuevas Terapias de Enfermedades reumáticas (GENTE)," Revista de Investigación Clínica, vol. 61, pp. 252-266, 2009.

[17] D. Alarcón-Segovia, J. A. Tumlin, R. A. Furie et al., "LJP 394 for the prevention of renal flare in patients with systemic lupus erythematosus: results from a randomized, doubleblind, placebo-controlled study," Arthritis and Rheumatism, vol. 48, no. 2, pp. 442-454, 2003.

[18] K. C. Kalunian, JC. Jr. Davis, J. T. Merrill, et al., “Treatment of systemic lupus erythematosus by inhibition of $\mathrm{T}$ cell costimulation with anti-CD154: a randomized, doubleblind, placebo-controlled trial," Arthritis \& Rheumatism, vol. 46, pp. 3251-3258, 2002.

[19] Y. Yao, L. Richman, B. W. Higgs et al., "Neutralization of interferon- $\alpha / \beta$-inducible genes and downstream effect in a phase I trial of an anti-interferon- $\alpha$ monoclonal antibody in systemic lupus erythematosus," Arthritis and Rheumatism, vol. 60, no. 6, pp. 1785-1796, 2009.

[20] M. Mohrs, B. Ledermann, G. Köhler, A. Dorfmüller, A. Gessner, and F. Brombacher, "Differences between IL-4and IL-4 receptor $\alpha$-deficient mice in chronic Leishmaniasis reveal a protective role for IL-13 receptor signaling," Journal of Immunology, vol. 162, no. 12, pp. 7302-7308, 1999.

[21] L. G. Criscione and D. S. Pisetsky, "B lymphocytes and systemic lupus erythematosus," Current Rheumatology Reports, vol. 5, no. 4, pp. 264-269, 2003.

[22] D. A. Horwitz, S. G. Zheng, J. Wang, and J. D. Gray, "Critical role of IL-2 and TGF- $\beta$ in generation, function and stabilization of Foxp3+ CD4+ Treg," European Journal of Immunology, vol. 38, no. 4, pp. 912-915, 2008.

[23] D. I. Mitsias, E. K. Kapsogeorgou, and H. M. Moutsopoulos, "Sjögren's syndrome: why autoimmune epithelitis?" Oral Diseases, vol. 12, no. 6, pp. 523-532, 2006.

[24] T. Hayashi, K. Hasegawa, and N. Ichinohe, "ICAM-1 expression on endothelium and systemic cytokine production in cutaneous neutrophilic leukocytoclastic vasculitis in $\mathrm{NZBXNZWF}_{1}$ mice," Histology and Histopathology, vol. 20, no. 1, pp. 45-52, 2005. 
[25] T. Hayashi, H. Hayashi, T. Fujii, C. Adachi, and K. Hasegawa, "Ultrastructure of myoepithelial cells as a target cell in sialoadenitis of submandibular glands of lupus-prone female NZBXNZWF 1 mice," Virchows Archiv, vol. 453, no. 2, pp. 177-188, 2008.

[26] J. Banchereau and V. Pascual, "Type I interferon in systemic lupus erythematosus and other autoimmune diseases," Immunity, vol. 25, no. 3, pp. 383-392, 2006.

[27] H.-K. Kang, M. Liu, and S. K. Datta, "Low-dose peptide tolerance therapy of lupus generates plasmacytoid dendritic cells that cause expansion of autoantigen-specific regulatory T cells and contraction of inflammatory Th17 cells," Journal of Immunology, vol. 178, no. 12, pp. 7849-7858, 2007.

[28] T. R. Mosmann and R. L. Coffman, "TH1 and TH2 cells: different patterns of lymphokine secretion lead to different functional properties," Annual Review of Immunology, vol. 7, pp. 145-173, 1989.

[29] A. N. Theofilopoulos, S. Koundouris, D. H. Kono, and B. R. Lawson, "The role of IFN- $\gamma$ in systemic erythematosus: a challenge tothe Th1/Th2 paradigm in autoimmunity," Arthritis Research, vol. 3, no. 3, pp. 136-141, 2001.

[30] J. E. Turner, O. M. Steinmetz, R. A. Stahl, and U. Panzer, "Targeting of Th1-associated chemokine receptors CXCR3 and CCR5 as therapeutic strategy for inflammatory diseases," Mini-Reviews in Medicinal Chemistry, vol. 7, no. 11, pp. 1089-1096, 2007.

[31] J. J. Hooks, H. M. Moutsopoulos, S. A. Geis, N. I. Stahl, J. L. Decker, and A. L. Notkins, "Immune interferon in the circulation of patients with autoimmune disease," New England Journal of Medicine, vol. 301, no. 1, pp. 5-8, 1979.

[32] H. Ishida, T. Muchamuel, S. Sakaguchi, S. Andrade, S. Menon, and M. Howard, "Continuous administration of anti-interleukin 10 antibodies delays onset of autoimmunity in NZB/W F1 mice," Journal of Experimental Medicine, vol. 179, no. 1, pp. 305-310, 1994.

[33] Y. Kaneko, S. Hirose, M. Abe, H. Yagita, K. Okumura, and T. Shirai, "CD40-mediated stimulation of B1 and B2 cells: implication in autoantibody production in murine lupus," European Journal of Immunology, vol. 26, no. 12, pp. 30613065, 1996.

[34] A. Nakajima, S. Hirose, H. Yagita, and K. Okumura, "Roles of IL-4 and IL-12 in the development of lupus in NZB/W F1 mice," Journal of Immunology, vol. 158, no. 3, pp. 1466-1472, 1997.

[35] S. L. Peng, J. Moslehi, and J. Craft, "Roles of interferon$\gamma$ and interleukin-4 in murine lupus," Journal of Clinical Investigation, vol. 99, no. 8, pp. 1936-1946, 1997.

[36] C. Haas, B. Ryffel, and M. Le Hir, "IFN- $\gamma$ receptor deletion prevents autoantibody production and glomerulonephritis in lupus-prone (NZB x NZW)F1 mice," Journal of Immunology, vol. 160, no. 8, pp. 3713-3718, 1998.

[37] K. M. Pollard, P. Hultman, and D. H. Kono, "Using singlegene deletions to identify checkpoints in the progression of systemic autoimmunity," Annals of the New York Academy of Sciences, vol. 987, pp. 236-239, 2003.

[38] H. B. Richards, M. Satoh, J. C. Jennette, B. P. Croker, H. Yoshida, and W. H. Reeves, "Interferon- $\gamma$ is required for lupus nephritis in mice treated with the hydrocarbon oil pristane," Kidney International, vol. 60, no. 6, pp. 2173-2180, 2001.

[39] D. L. Smith-Bouvier, A. A. Divekar, M. Sasidhar et al., "A role for sex chromosome complement in the female bias in autoimmune disease," Journal of Experimental Medicine, vol. 205, no. 5, pp. 1099-1108, 2008.
[40] M. Sugiyama, M. Funauchi, T. Yamagata et al., "Predominant inhibition of Th1 cytokines in New Zealand black/white $\mathrm{F}_{1}$ mice treated with FK506," Scandinavian Journal of Rheumatology, vol. 33, no. 2, pp. 108-114, 2004.

[41] S. Takahashi, L. Fossati, M. Iwamoto et al., "Imbalance towards Th1 predominance is associated with acceleration of lupus-like autoimmune syndrome in MRL mice," Journal of Clinical Investigation, vol. 97, no. 7, pp. 1597-1604, 1996.

[42] Y. Tokano, S. Morimoto, H. Kaneko et al., "Levels of IL-12 in the sera of patients with systemic lupus erythematosus (SLE)-relation to Th1- and Th2-derived cytokines," Clinical and Experimental Immunology, vol. 116, no. 1, pp. 169-173, 1999.

[43] M. Tucci, L. Lombardi, H. B. Richards, F. Dammacco, and F. Silvestris, "Overexpression of interleukin-12 and T helper 1 predominance in lupus nephritis," Clinical and Experimental Immunology, vol. 154, no. 2, pp. 247-254, 2008.

[44] N. Calvani, H. B. Richards, M. Tucci, G. Pannarale, and F. Silvestris, "Up-regulation of IL-18 and predominance of a Th1 immune response is a hallmark of lupus nephritis," Clinical and Experimental Immunology, vol. 138, no. 1, pp. 171-178, 2004.

[45] F. Favilli, C. Anzilotti, L. Martinelli et al., "IL-18 activity in systemic lupus erythematosus," Annals of the New York Academy of Sciences, vol. 1173, pp. 301-309, 2009.

[46] V. Rus, S. P. Atamas, V. Shustova et al., "Expression of cytokine- and chemokine-related genes in peripheral blood mononuclear cells from lupus patients by cDNA array," Clinical Immunology, vol. 102, no. 3, pp. 283-290, 2002.

[47] K. Hasegawa and T. Hayashi, "Synthetic CpG oligodeoxynucleotides accelerate the development of lupus nephritis during preactive phase in $\mathrm{NZB} \times \mathrm{NZWF}_{1}$ mice," Lupus, vol. 12, no. 11, pp. 838-845, 2003.

[48] S. Shimizu, N. Sugiyama, K. Masutani et al., "Membranous glomerulonephritis development with Th2-type immune deviations in MRL/lpr mice deficient for IL-27 receptor (WSX-1)," Journal of Immunology, vol. 175, no. 11, pp. 71857192, 2005.

[49] R. R. Singh, V. Saxena, S. Zang et al., "Differential contribution of IL-4 and STAT6 vs STAT4 to the development of lupus nephritis," Journal of Immunology, vol. 170, no. 9, pp. 48184825, 2003.

[50] W. E. Paul and R. A. Seder, "Lymphocyte responses and cytokines," Cell, vol. 76, no. 2, pp. 241-251, 1994.

[51] Y. Borel, R. M. Lewis, J. Andre-Schwartz, B. D. Stollar, and E. Diener, "Treatment of lupus nephritis in adult (NZB + $\mathrm{NZW}) \mathrm{F}_{1}$ mice by cortisone-facilitated tolerance to nucleic acid antigens," Journal of Clinical Investigation, vol. 61, no. 2, pp. 276-286, 1978.

[52] I. Gursel, M. Gursel, H. Yamada, K. J. Ishii, F. Takeshita, and D. M. Klinman, "Repetitive elements in mammalian telomeres suppress bacterial DNA-induced immune activation," Journal of Immunology, vol. 171, no. 3, pp. 1393-1400, 2003.

[53] L. Dong, S. Ito, K. J. Ishii, and D. M. Klinman, "Suppressive oligodeoxynucleotides delay the onset of glomerulonephritis and prolong survival in lupus-prone NZB x NZW mice," Arthritis and Rheumatism, vol. 52, no. 2, pp. 651-658, 2005.

[54] R. A. Zeuner, D. Verthelyi, M. Gursel, K. J. Ishii, and D. M. Klinman, "Influence of stimulatory and suppressive DNA motifs on host susceptibility to inflammatory arthritis," Arthritis and Rheumatism, vol. 48, no. 6, pp. 1701-1707, 2003. 
[55] K. Sano, H. Shirota, T. Terui, T. Hattori, and G. Tamura, "Oligodeoxynucleotides without $\mathrm{CpG}$ motifs work as adjuvant for the induction of Th2 differentiation in a sequenceindependent manner," Journal of Immunology, vol. 170, no. 5, pp. 2367-2373, 2003.

[56] H. Shirota, M. Gursel, and D. M. Klinman, "Suppressive oligodeoxynucleotides inhibit Th1 differentiation by blocking IFN- $\gamma$ - and IL-12-mediated signaling," Journal of Immunology, vol. 173, no. 8, pp. 5002-5007, 2004.

[57] L. Dong, S.-I. Ito, K. J. Ishii, and D. M. Klinman, "Suppressive oligonucleotides protect against collagen-induced arthritis in mice," Arthritis and Rheumatism, vol. 50, no. 5, pp. 16861689, 2004.

[58] T. Hayashi, Y. Yasutomi, K. Hasegawa, Y. Sasaki, and T. Onodera, "Interleukin-4-expressing plasmid DNA inhibits reovirus type-2-triggered autoimmune insulitis in DBA/1 J suckling mice," International Journal of Experimental Pathology, vol. 84, no. 2, pp. 101-106, 2003.

[59] Y. Tominaga, M. Nagata, H. Yasuda et al., "Administration of IL-4 prevents autoimmune diabetes but enhances pancreatic insulitis in NOD mice," Clinical Immunology and Immunopathology, vol. 86, no. 2, pp. 209-218, 1998.

[60] P. J. Conlon, S. Tyler, K. H. Grabstein, and P. Morrissey, "Interleukin-4 (B-cell stimulatory factor-1) augments the in vivo generation of cytotoxic cells in immunosuppressed animals," Biotechnology Therapeutics, vol. 1, no. 1, pp. 31-41, 1989.

[61] E. M. Sloane, R. G. Soderquist, S. F. Maier, M. J. Mahoney, L. R. Watkins, and E. D. Milligan, "Long-term control of neuropathic pain in a non-viral gene therapy paradigm," Gene Therapy, vol. 16, no. 4, pp. 470-475, 2009.

[62] S. Al-Mutairi, A. Al-Awadhi, R. Raghupathy et al., "Lupus patients with pulmonary involvement have a proinflammatory cytokines profile," Rheumatology International, vol. 27, no. 7, pp. 621-630, 2007.

[63] M.-L. Santiago, L. Fossati, C. Jacquet, W. Müller, S. Izui, and L. Reininger, "Interleukin-4 protects against a genetically linked lupus-like autoimmune syndrome," Journal of Experimental Medicine, vol. 185, no. 1, pp. 65-70, 1997.

[64] W. Muller, R. Kuhn, and K. Rajewsky, "Major histocompatibility complex class II hyperexpression on B cells in interleukin 4-transgenic mice does not lead to B cell proliferation and hypergammaglobulinemia," European Journal of Immunology, vol. 21, no. 4, pp. 921-925, 1991.

[65] L. M. C. C. Leal, D. W. Moss, R. Kuhn, W. Muller, and F. Y. Liew, "Interleukin-4 transgenic mice of resistant background are susceptible to Leishmania major infection," European Journal of Immunology, vol. 23, no. 2, pp. 566-569, 1993.

[66] A. Sher and R. L. Coffman, "Regulation of immunity to parasites by T cells and T cell-derived cytokines," Annual Review of Immunology, vol. 10, pp. 385-409, 1992.

[67] M. Röcken, M. Racke, and E. M. Shevach, "IL-4-induced immune deviation as antigen-specific therapy for inflammatory autoimmune disease," Immunology Today, vol. 17, no. 5, pp. 225-231, 1996.

[68] T. Hayashi, K. Hasegawa, Y. Sasaki, T. Mori, C. Adachi, and K. Maeda, "Systemic administration of interleukin-4 expressing plasmid DNA delays the development of glomerulonephritis and prolongs survival in lupus-prone female NZB $\times$ NZW $\mathrm{F}_{1}$ mice," Nephrology Dialysis Transplantation, vol. 22, no. 11, pp. 3131-3138, 2007.
[69] Y. Nitta, F. Tashiro, M. Tokui et al., "Systemic delivery of interleukin 10 by intramuscular injection of expression plasmid DNA prevents autoimmune diabetes in nonobese diabetic mice," Human Gene Therapy, vol. 9, no. 12, pp. 1701-1707, 1998.

[70] M. Lee, J. K. Jae, S.-O. Han, K. S. Ko, and S. W. Ki, "Prevention of autoimmune insulitis by delivery of interleukin4 plasmid using a soluble and biodegradable polymeric carrier," Pharmaceutical Research, vol. 19, no. 3, pp. 246-249, 2002.

[71] C. A. Piccirillo and G. J. Prud'homme, "Immune modulation by plasmid DNA-mediated cytokine gene transfer," Current Pharmaceutical Design, vol. 9, no. 1, pp. 83-94, 2003.

[72] D. M. Klinman, A.-K. Yi, S. L. Beaucage, J. Conover, and A. M. Krieg, "CpG motifs present in bacterial DNA rapidly induce lymphocytes to secrete interleukin 6, interleukin 12, and interferon $\gamma$," Proceedings of the National Academy of Sciences of the United States of America, vol. 93, no. 7, pp. 2879-2883, 1996.

[73] D. S. Pisetsky, "Immune activation by bacterial DNA: a new genetic code," Immunity, vol. 5, no. 4, pp. 303-310, 1996.

[74] O. Mazda, "Improvement of nonviral gene therapy by Epstein-Barr virus (EBV)-based plasmid vectors," Current Gene Therapy, vol. 2, no. 3, pp. 379-392, 2002.

[75] P. Casali and A. L. Notkins, "CD5 ${ }^{+}$B lymphocytes, polyreactive antibodies and the human B-cell repertoire," Immunology Today, vol. 10, no. 11, pp. 364-368, 1989.

[76] X. Wen, D. Zhang, Y. Kikuchi et al., "Transgene-mediated hyper-expression of IL-5 inhibits autoimmune disease but increases the risk of B cell chronic lymphocytic leukemia in a model of murine lupus," European Journal of Immunology, vol. 34, no. 10, pp. 2740-2749, 2004.

[77] E. Hagiwara, T. Okubo, I. Aoki et al., "IL-12-encoding plasmid has a beneficial effect on spontaneous autoimmune disease in MRL/MP-lpr/lpr mice," Cytokine, vol. 12, no. 7, pp. 1035-1041, 2000.

[78] R. A. Mageed and G. J. Prud'homme, "Immunopathology and the gene therapy of lupus," Gene Therapy, vol. 10, no. 10, pp. 861-874, 2003.

[79] L. Ozmen, D. Roman, M. Fountoulakis, G. Schmid, B. Ryffel, and G. Garotta, "Experimental therapy of systemic lupus erythematosus: the treatment of NZB/W mice with mouse soluble interferon- $\gamma$ receptor inhibits the onset of glomerulonephritis," European Journal of Immunology, vol. 25, no. 1, pp. 6-12, 1995.

[80] B. R. Lawson, G. J. Prud'homme, Y. Chang et al., "Treatment of murine lupus with cDNA encoding IFN- $\gamma$ R/Fc," Journal of Clinical Investigation, vol. 106, no. 2, pp. 207-215, 2000.

[81] G. J. Prud'homme, "Gene therapy of autoimmune diseases with vectors encoding regulatory cytokines or inflammatory cytokine inhibitors," Journal of Gene Medicine, vol. 2, no. 4, pp. 222-232, 2000.

[82] P. Bossù, D. Neumann, E. Del Giudice et al., "IL-18 cDNA vaccination protects mice from spontaneous lupus-like autoimmune disease," Proceedings of the National Academy of Sciences of the United States of America, vol. 100, no. 2, pp. 14181-14186, 2003.

[83] E. Esfandiari, I. B. McInnes, G. Lindop et al., "A proinflammatory role of IL-18 in the development of spontaneous autoimmune disease," Journal of Immunology, vol. 167, no. 9, pp. 5338-5347, 2001. 
[84] A. Schwarting, G. Tesch, K. Kinoshita, R. Maron, H. L. Weiner, and V. R. Kelley, "IL-12 drives IFN- $\gamma$-dependent autoimmune kidney disease in MRL-Fas(lpr) mice," Journal of Immunology, vol. 163, no. 12, pp. 6884-6891, 1999.

[85] M. C. Park, Y. B. Park, and S. K. Lee, "Elevated interleukin18 levels correlated with disease activity in systemic lupus erythematosus," Clinical Rheumatology, vol. 23, no. 3, pp. 225-229, 2004.

[86] A. Wozniacka, A. Lesiak, J. Narbutt, D. P. McCauliffe, and A. Sysa-Jedrzejowska, "Chloroquine treatment influences proinflammatory cytokine levels in systemic lupus erythematosus patients," Lupus, vol. 15, no. 5, pp. 268-275, 2006.

[87] D. Neumann, T. Tschernig, D. Popa et al., "Injection of IL-12and IL-18-encoding plasmids ameliorates the autoimmune pathology of MRL/Mp-Tnfrsf6lpr mice: synergistic effect on autoimmune symptoms," International Immunology, vol. 18, no. 12, pp. 1779-1787, 2006.

[88] E. Raz, J. Dudler, M. Lotz et al., "Modulation of disease activity in murine systemic lupus erythematosus by cytokine gene delivery," Lupus, vol. 4, no. 4, pp. 286-292, 1995.

[89] M. L. Huggins, F.-P. Huang, D. Xu, G. Lindop, and D. I. Stott, "Modulation of autoimmune disease in the MRL-lpr/lpr mouse by IL- 2 and TGF- $\beta 1$ gene therapy using attenuated Salmonella typhimurium as gene carrier," Lupus, vol. 8, no. 1, pp. 29-38, 1999.

[90] J. C. Gutierrez-Ramos, J. L. Andreu, Y. Revilla, E. Vinuela, and C. Martinez, "Recovery from autoimmunity of MRL/lpr mice after infection with an interleukin-2/vaccinia recombinant virus," Nature, vol. 346, no. 6281, pp. 271-274, 1990.

[91] X. Wang, W. Huang, L. E. Schiffer et al., "Effects of antiCD154 treatment on B cells in murine systemic lupus erythematosus," Arthritis and Rheumatism, vol. 48, no. 2, pp. 495-506, 2003.

[92] M. Takiguchi, M. Murakami, I. Nakagawa, I. Saito, A. Hashimoto, and T. Uede, "CTLA4IgG gene delivery prevents autoantibody production and lupus nephritis in MRL/lpr mice," Life Sciences, vol. 66, no. 11, pp. 991-1001, 2000.

[93] M. Mihara, I. Tan, Y. Chuzhin et al., "CTLA4Ig inhibits T cell-dependent B-cell maturation in murine systemic lupus erythematosus," Journal of Clinical Investigation, vol. 106, no. 1, pp. 91-101, 2000.

[94] X. Ye, T. Zhu, S. Bastacky, T. McHale, J. Li, and X. Xiao, "Prevention and reversal of lupus in NZB/NZW mice by costimulatory blockade with adeno-associated virus-mediated gene transfer," Arthritis and Rheumatism, vol. 52, no. 12, pp. 3975-3986, 2005.

[95] H. Ding, X. Wu, J. Wu et al., "Delivering PD-1 inhibitory signal concomitant with blocking ICOS co-stimulation suppresses lupus-like syndrome in autoimmune BXSB mice," Clinical Immunology, vol. 118, no. 2-3, pp. 258-267, 2006.

[96] H. Nishimura and T. Honjo, "PD-1: an inhibitory immunoreceptor involved in peripheral tolerance," Trends in Immunology, vol. 22, no. 5, pp. 265-268, 2001.

[97] G. J. Freeman, A. J. Long, Y. Iwai et al., "Engagement of the PD-1 immunoinhibitory receptor by a novel B7 family member leads to negative regulation of lymphocyte activation," Journal of Experimental Medicine, vol. 192, no. 7, pp. 1027-1034, 2000.

[98] L. L. Carter, L. A. Fouser, J. Jussif et al., "PD-1:PD-L inhibitory pathway affects both $\mathrm{CD}^{+}$and $\mathrm{CD}^{+} \mathrm{T}$ cells and is overcome by IL-2," European Journal of Immunology, vol. 32, no. 3, pp. 634-643, 2002.
[99] X. Zhong, C. Bai, W. Gao, T. B. Strom, and T. L. Rothstein, "Suppression of expression and function of negative immune regulator PD-1 by certain pattern recognition and cytokine receptor signals associated with immune system danger," International Immunology, vol. 16, no. 8, pp. 1181-1188, 2004.

[100] C. Dong, A. E. Juedes, U.-A. Temann et al., "ICOS costimulatory receptor is essential for T-cell activation and function," Nature, vol. 409, no. 6816, pp. 97-101, 2001.

[101] A. J. McAdam, R. J. Greenwald, M. A. Levin et al., "Icos is critical for CD40-mediated antibody class switching," Nature, vol. 409, no. 6816, pp. 102-105, 2001.

[102] A. Tafuri, A. Shahinian, F. Bladt et al., "ICOS is essential for effective T-helper-cell responses," Nature, vol. 409, no. 6816, pp. 105-109, 2001.

[103] W. Liu, A. Szalai, L. Zhao et al., "Control of spontaneous B lymphocyte autoimmunity with adenovirus-encoded soluble TACI," Arthritis and Rheumatism, vol. 50, no. 6, pp. 18841896, 2004.

[104] Y. S. Haviv, K. Takayama, P. A. Nagi et al., "Modulation of renal glomerular disease using remote delivery of adenoviralencoded soluble type II TGF- $\beta$ receptor fusion molecule," Journal of Gene Medicine, vol. 5, no. 10, pp. 839-851, 2003.

[105] V. Pascual, L. Farkas, and J. Banchereau, "Systemic lupus erythematosus: all roads lead to type I interferons," Current Opinion in Immunology, vol. 18, no. 6, pp. 676-682, 2006.

[106] D. A. Horwitz, "Regulatory T cells in systemic lupus erythematosus: past, present and future," Arthritis Research and Therapy, vol. 10, no. 6, article 227, 2008.

[107] C. Pasare and R. Medzhitov, "Toll pathway-dependent blockade of $\mathrm{CD} 4^{+} \mathrm{CD} 25^{+} \mathrm{T}$ cell-mediated suppression by dendritic cells," Science, vol. 299, no. 5609, pp. 1033-1036, 2003.

[108] J. Banchereau, F. Briere, C. Caux et al., "Immunobiology of dendritic cells," Annual Review of Immunology, vol. 18, pp. 767-811, 2000.

[109] Y.-J. Liu, "IPC: professional type 1 interferon-producing cells and plasmacytoid dendritic cell precursors," Annual Review of Immunology, vol. 23, pp. 275-306, 2005.

[110] M. Mohty, A. Vialle-Castellano, J. A. Nunes, D. Isnardon, D. Olive, and B. Gaugler, "IFN- $\alpha$ skews monocyte differentiation into Toll-like receptor 7-expressing dendritic cells with potent functional activities," Journal of Immunology, vol. 171, no. 7, pp. 3385-3393, 2003.

[111] A. M. Boruchov, G. Heller, M.-C. Veri, E. Bonvini, J. V. Ravetch, and J. W. Young, "Activating and inhibitory IgG Fc receptors on human DCs mediate opposing functions," Journal of Clinical Investigation, vol. 115, no. 10, pp. 29142923, 2005.

[112] K. M. Dhodapkar, J. L. Kaufman, M. Ehlers et al., "Selective blockade of inhibitory Fc $\gamma$ receptor enables human dendritic cell maturation with IL-12p70 production and immunity to antibody-coated tumor cells," Proceedings of the National Academy of Sciences of the United States of America, vol. 102, no. 8, pp. 2910-2915, 2005.

[113] G. Grouard, M.-C. Rissoan, L. Filgueira, I. Durand, J. Banchereau, and Y.-J. Liu, "The enigmatic plasmacytoid T cells develop into dendritic cells with interleukin (IL)-3 and CD40-ligand," Journal of Experimental Medicine, vol. 185, no. 6, pp. 1101-1111, 1997.

[114] J. Vollmer, S. Tluk, C. Schmitz et al., "Immune stimulation mediated by autoantigen binding sites within small nuclear RNAs involves Toll-like receptors 7 and 8," Journal of Experimental Medicine, vol. 202, no. 11, pp. 1575-1585, 2005. 
[115] M. A. Gill, P. Blanco, E. Arce, V. Pascual, J. Banchereau, and A. K. Palucka, "Blood dendritic cells and DC-poietins in systemic lupus erythematosus," Human Immunology, vol. 63, no. 12, pp. 1172-1180, 2002.

[116] C. O. Jacob and H. O. McDevitt, "Tumour necrosis factor- $\alpha$ in murine autoimmune 'lupus' nephritis," Nature, vol. 331, no. 6154, pp. 356-358, 1988.

[117] E. Toubi, "The role of $\mathrm{CD}^{+} \mathrm{CD} 25^{+} \mathrm{T}$ regulatory cells in autoimmune diseases," Clinical Reviews in Allergy and Immunology, vol. 34, no. 3, pp. 338-344, 2008.

[118] T. Hayashi, "Environmental factors and concepts in the induction of type 1 diabetes," in Hand book of Type 1 Diabetes Mellitus: Etiology, Diagnosis and Treatment, L. Aucoin and T. Prideux, Eds., chapter 1, pp. 1-45, 2010.

[119] T. Hayashi, K. Hasegawa, and C. Adachi, "Elimination of $\mathrm{CD} 4{ }^{+} \mathrm{CD} 25^{+} \mathrm{T}$ cell accelerates the development of glomerulonephritis during the preactive phase in autoimmuneprone female NZB $\times \mathrm{NZWF}_{1}$ mice," International Journal of Experimental Pathology, vol. 86, no. 5, pp. 289-296, 2005.

[120] T. Hayashi, C. Adachi, and K. Hasegawa, "Systemic treatment of anti-CD $4^{+} \mathrm{CD} 25^{+} \mathrm{T}$ cell monoclonal antibody exacerbates sialoadenitis in submandibular glands during the early life in lupus-prone female NZB $\times \mathrm{NZWF}_{1}$ mice," Journal of Oral Pathology and Medicine, vol. 38, no. 2, pp. 234-240, 2009.

[121] K. J. Scalapino, Q. Tang, J. A. Bluestone, M. L. Bonyhadi, and D. I. Daikh, "Suppression of disease in New Zealand Black/New Zealand White lupus-prone mice by adoptive transfer of ex vivo expanded regulatory T cells," Journal of Immunology, vol. 177, no. 3, pp. 1451-1459, 2006.

[122] R. Y. Lan, A. A. Ansari, Z.-X. Lian, and M. E. Gershwin, "Regulatory T cells: development, function and role in autoimmunity," Autoimmunity Reviews, vol. 4, no. 6, pp. 351-363, 2005.

[123] C. Baecher-Allan, J. A. Brown, G. J. Freeman, and D. A. Hafler, "CD4 ${ }^{+} \mathrm{CD} 25^{\text {high }}$ regulatory cells in human peripheral blood," Journal of Immunology, vol. 167, no. 3, pp. 12451253, 2001.

[124] S. G. Zheng, J. H. Wang, M. N. Koss, F. Quismorio Jr., J. D. Gray, and D. A. Horwitz, "CD4 ${ }^{+}$and $\mathrm{CD}^{+}$regulatory $\mathrm{T}$ cells generated ex vivo with IL- 2 and TGF- $\beta$ suppress a stimulatory graft-versus-host disease with a lupus-like syndrome," Journal of Immunology, vol. 172, no. 3, pp. 15311539, 2004.

[125] H. J. P. M. Koenen, R. L. Smeets, P. M. Vink, E. van Rijssen, A. M. H. Boots, and I. Joosten, "Human CD25 high Foxp3pos regulatory T cells differentiate into IL-17 producing cells," Blood, vol. 112, no. 6, pp. 2340-2352, 2008.

[126] L. Xu, A. Kitani, I. Fuss, and W. Strober, "Cutting edge: regulatory $\mathrm{T}$ cells induce $\mathrm{CD} 4^{+} \mathrm{CD} 25^{-}$Foxp $^{-} \mathrm{T}$ cells or are self-induced to become Th17 cells in the absence of exogenous TGF- $\beta$," Journal of Immunology, vol. 178, no. 11, pp. 6725-6729, 2007.

[127] Q. Tang, J. Y. Adams, A. J. Tooley et al., "Visualizing regulatory $\mathrm{T}$ cell control of autoimmune responses in nonobese diabetic mice," Nature Immunology, vol. 7, no. 1, pp. 83-92, 2006.

[128] C. E. Tadokoro, G. Shakhar, S. Shen et al., "Regulatory T cells inhibit stable contacts between $\mathrm{CD} 4^{+} \mathrm{T}$ cells and dendritic cells in vivo," Journal of Experimental Medicine, vol. 203, no. 3, pp. 505-511, 2006.

[129] M. Terme, N. Chaput, B. Combadiere, M. Averil, T. Ohteki, and L. Zitvogel, "Regulatory T cells control dendritic cell/NK cell cross-talk in lymph nodes at the steady state by inhibiting
CD4 ${ }^{+}$self-reactive T cells," Journal of Immunology, vol. 180, no. 7, pp. 4679-4686, 2008.

[130] D.-M. Zhao, A. M. Thornton, R. J. DiPaolo, and E. M. Shevach, "Activated $\mathrm{CD} 4^{+} \mathrm{CD} 25^{+} \mathrm{T}$ cells selectively kill B lymphocytes," Blood, vol. 107, no. 10, pp. 3925-3932, 2006.

[131] M. Giroux, E. Yurchenko, J. St-Pierre, C. A. Piccirillo, and C. Perreault, "T regulatory cells control numbers of NK cells and $\mathrm{CD} 8 \alpha+$ immature dendritic cells in the lymph node paracortex," Journal of Immunology, vol. 179, no. 7, pp. 44924502, 2007.

[132] W.-P. Min, D. Zhou, T. E. Ichim et al., "Inhibitory feedback loop between tolerogenic dendritic cells and regulatory $\mathrm{T}$ cells in transplant tolerance," Journal of Immunology, vol. 170, no. 3, pp. 1304-1312, 2003.

[133] Y. Cai, S. Rodriguez, R. Rameswaran, R. Draghia-Akli, R. J. Juba Jr., and H. Hebel, "Production of pharmaceuticalgrade plasmids at high concentration and high supercoiled percentage," Vaccine, vol. 28, no. 8, pp. 2046-2052, 2010.

[134] C. Voss, "Production of plasmid DNA for pharmaceutical use," Biotechnology Annual Review, vol. 13, pp. 201-222, 2007.

[135] M. Przybylowski, S. Bartido, O. Borquez-Ojeda, M. Sadelain, and I. Rivière, "Production of clinical-grade plasmid DNA for human Phase I clinical trials and large animal clinical studies," Vaccine, vol. 25, no. 27, pp. 5013-5024, 2007.

[136] S. K. Tripathy, E. C. Svensson, H. B. Black et al., "Long-term expression of erythropoietin in the systemic circulation of mice after intramuscular injection of a plasmid DNA vector," Proceedings of the National Academy of Sciences of the United States of America, vol. 93, no. 20, pp. 10876-10880, 1996.

[137] J. A. Wolff, J. J. Ludtke, G. Acsadi, P. Williams, and A. Jani, "Long-term persistence of plasmid DNA and foreign gene expression in mouse muscle," Human Molecular Genetics, vol. 1, no. 6, pp. 363-369, 1992.

[138] J. A. Wolff, R. W. Malone, P. Williams, et al., "Direct gene transfer into mouse muscle in vivo," Science, vol. 247, no. 4949, pp. 1465-1468, 1990.

[139] C. H. Evans, P. D. Robbins, S. C. Ghivizzani, et al., "Clinical trial to assess the safety, feasibility, and efficacy of transferring a potentially anti-arthritic cytokine gene to human joints with rheumatoid arthritis," Human Gene Therapy, vol. 7, no. 10, pp. 1261-1280, 1996.

[140] C. H. Evans, S. C. Ghivizzani, and P. D. Robbins, "Gene therapy of the rheumatic diseases: 1998 to 2008," Arthritis Research and Therapy, vol. 11, no. 1, article 209, 2009.

[141] P. Wehling, J. Reinecke, A. W. A. Baltzer et al., "Clinical responses to gene therapy in joints of two subjects with rheumatoid arthritis," Human Gene Therapy, vol. 20, no. 2, pp. 97-101, 2009.

[142] H. L. Davis, B. A. Demeneix, B. Quantin, J. Coulombe, and R. G. Whalen, "Plasmid DNA is superior to viral vectors for direct gene transfer into adult mouse skeletal muscle," Human Gene Therapy, vol. 4, no. 6, pp. 733-740, 1993.

[143] V. C. Kyttaris, P. P. Sfikakis, Y.-T. Juang, and G. C. Tsokos, "Gene therapy in systemic lupus erythematosus," Current Gene Therapy, vol. 5, no. 6, pp. 677-684, 2005.

[144] T. Hayashi, M. Morimoto, H. Iwata, and T. Onodera, "Possible involvement of IL-12 in reovirus type-2-induced diabetes in newborn DBA/1 mice," Scandinavian Journal of Immunology, vol. 53, no. 6, pp. 572-578, 2001.

[145] K. Liu and C. Mohan, "What do mouse models teach us about human SLE?” Clinical Immunology, vol. 119, no. 2, pp. 123-130, 2006 
[146] P. Pisitkun, J. A. Deane, M. J. Difilippantonio, T. Tarasenko, A. B. Satterthwaite, and S. Bolland, "Autoreactive B cell responses to RNA-related antigens due to TLR7 gene duplication," Science, vol. 312, no. 5780, pp. 1669-1672, 2006.

[147] S. Subramanian, K. Tus, Q.-Z. Li et al., "A Tlr7 translocation accelerates systemic autoimmunity in murine lupus," Proceedings of the National Academy of Sciences of the United States of America, vol. 103, no. 26, pp. 9970-9975, 2006. 


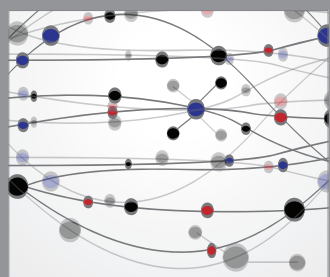

The Scientific World Journal
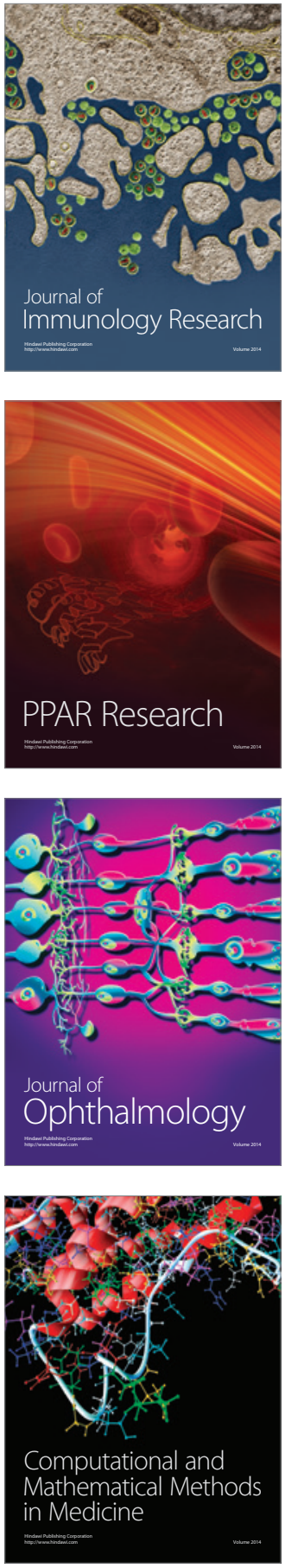

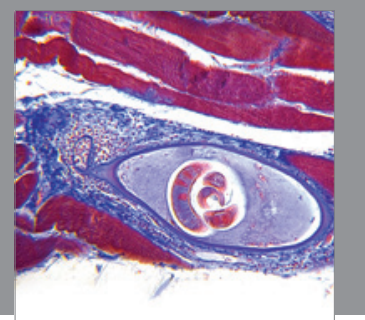

Gastroenterology

Research and Practice
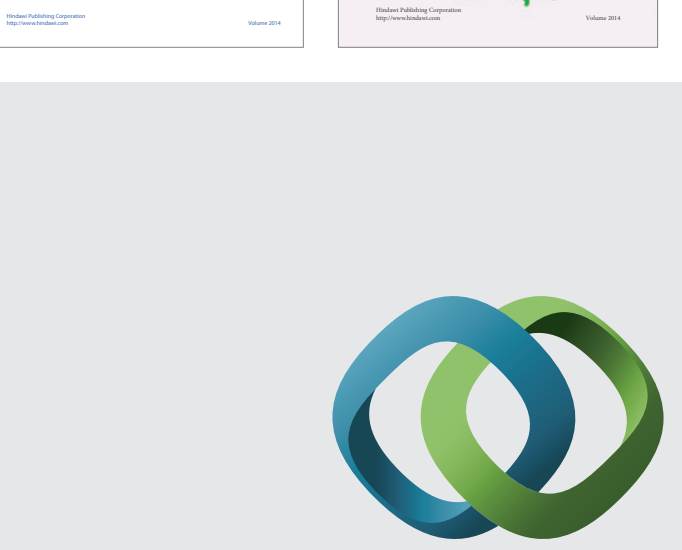

\section{Hindawi}

Submit your manuscripts at

http://www.hindawi.com
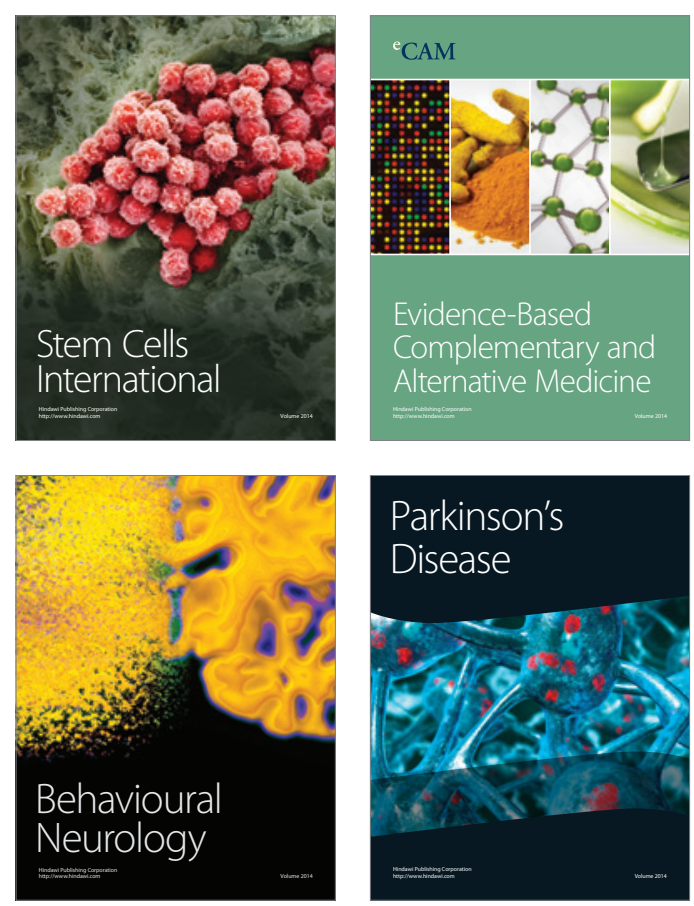

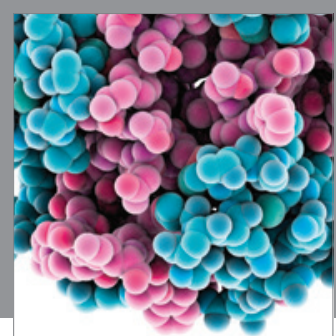

Journal of
Diabetes Research

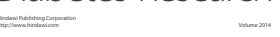

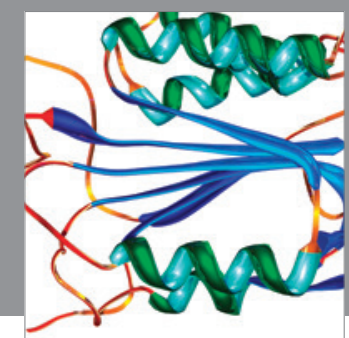

Disease Markers
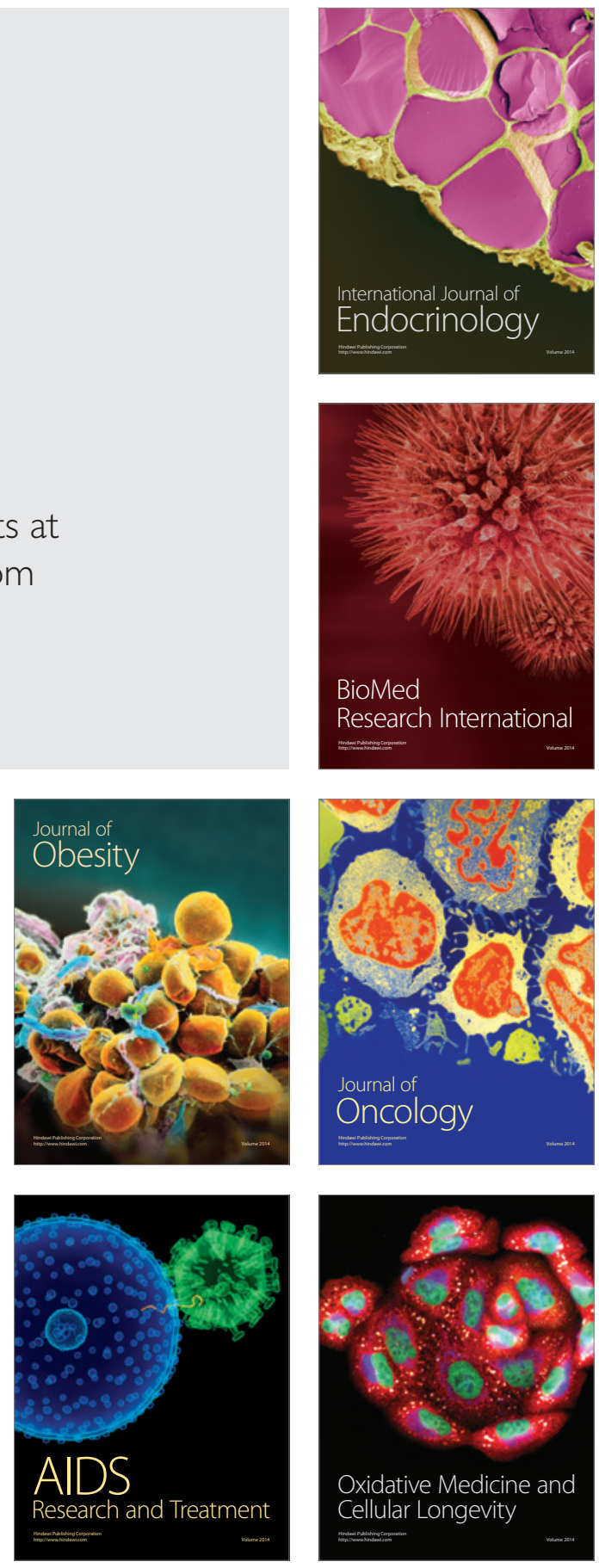